\title{
Mesoscale FDDA Experiments with WTM and ACARS Data
}

\author{
Chia-Bo Chang ${ }^{*}, 1$ and Robert Dumais ${ }^{2}$ \\ ${ }^{I}$ Department of Geosciences, Texas Tech University, Lubbock, Texas 79409, USA \\ ${ }^{2}$ Army Research Laboratory, White Sands Missile Range, NM 88002, USA
}

\begin{abstract}
This is a real-data Four Dimensional Data Assimilation (FDDA) study using MM5 in conjunction with West Texas Mesonet surface observations and ACARS (Aircraft Communications Addressing and Reporting System) profile data collected by commercial aircraft during both en route and ascent/descent phases of their flights. The high-frequency mesonet data and ACARS wind and temperature profiles are ideal for testing the effects of FDDA on short-term mesoscale numerical weather prediction. The mesonet experiments involved 35 sites with an average horizontal spacing of about $30 \mathrm{~km}$, while in the ACARS case ninety five profiles were used. Results indicated that nudging the MM5 model with the surface-based data over the relatively small area of the mesonet domain had limited impact on the model's performance. In the ACARS runs, FDDA had long-lasting impact throughout the entire model atmosphere. FDDA appeared to improve the quantitative precipitation forecasting skill of MM5 and reduce slightly the model's warm bias at the surface. The study suggests that ACARS has potential to significantly enhance our expertise in short-term mesoscale modeling and to support the need to rapidly and accurately adjust high-resolution meteorological model forecasts to real-time observations.
\end{abstract}

\section{INTRODUCTION}

The focus of this paper is on mesoscale modeling and FDDA. Because of its small spatial size mesoscale weather is strongly influenced by fast-changing local conditions such as cloud, friction, and surface heating. To catch these fastchanging local events so as to maximize the model performance, state-of-the-art mesoscale numerical weather prediction (NWP) often makes use of FDDA of high-frequency observations to update the model state during the time integration [1]. The West Texas Mesonet (WTM) surface observations reported at five minute frequency, along with the NOAA ACARS observations taken by commercial aircraft at about every ten minutes while crisscrossing the nation [2], offer valuable data for mesoscale FDDA. Other researchers such as those at NCAR's Research Applications Laboratory $[3,4]$ have provided some previous examination of the impact and quality of ACARS in mesoscale FDDA. A better understanding of how to take advantage of these high resolution data sets can significantly advance our expertise in mesoscale NWP.

In this study, real-data assimilation experiments based on the WTM surface tower data and ACARS profile data were conducted using the MM5 prediction system [5] to reveal the impact of high-frequency FDDA on mesoscale NWP. We were particularly interested in the data's impact on boundary layer (BL) and precipitation forecasting.

As shown later, the WTM observations were confined to a relatively small domain over the Southern Plains, while the ACARS observations covered a much more widespread area. The empirical method known as observational nudging

*Address correspondence to this author at the Department of Geosciences, Texas Tech University, Lubbock, Texas 79409, USA;

E-mail: CHIA-BO.CHANG@ttu.edu
(Newtonian relaxation) [6] was employed in the MM5 FDDA.

There are other more sophisticated data assimilation methods involving the Kalman filter or three-dimensional variational (3DVAR) procedures [7], but these advanced treatments are much more computationally intensive and require background information generally not available in a fast-response scenario, e.g., prediction of atmospheric boundary layer dispersion for emergency response. We believe that the Newtonian relaxation technique represents a good balance between complexity, timeliness, and accuracy, which is an important guiding principle for short-term prediction and nowcasting.

Relevant scientific questions examined include:

a) can data assimilation using high frequency surface observations alone significantly influence the model forecasts?

b) how sensitive are the model forecasts to changes in (1) the nudging parameters and (2) the input ACARS data density?

c) how does the model's quantitative precipitation forecasting (QPF) respond to FDDA?

The rest of this paper is organized as follows: Sections 2 and 3 give, respectively, a brief overview of WTM and ACARS including the quality of the data sets. Section 4 describes the data assimilation procedures, and synthesizes the results of three real-data case studies. Major findings and conclusions are summarized in Section 5.

\section{WTM}

A detailed technical overview of the WTM surface stations and completed site locations can be found in [8]. Fig. (1) shows a sample plot of WTM surface tower data over an 
area of about $300 \mathrm{~km}$ (west to east) by $350 \mathrm{~km}$ (south to north). Each square box of approximately $50 \mathrm{~km}$ by $50 \mathrm{~km}$ represents a county. There are 45 observation sites with an average spacing close to $30 \mathrm{~km}$. The surface data are now being distributed in real time via the Internet to users accessing the WTM homepage (www.mesonet.ttu.edu). The mesonet online data are updated in real time every five minutes. The National Weather Service (NWS) has been incorporating these observations into their hourly weather roundup product since 2001 and is available to the public and news media. The redundancy of data sources will ensure that data used for any projects has a backup in case of a server failure at Reese Center, which is located in the box of $4^{\text {th }}$ row from the bottom and $3^{\text {rd }}$ column from the Texas-New Mexico state line.

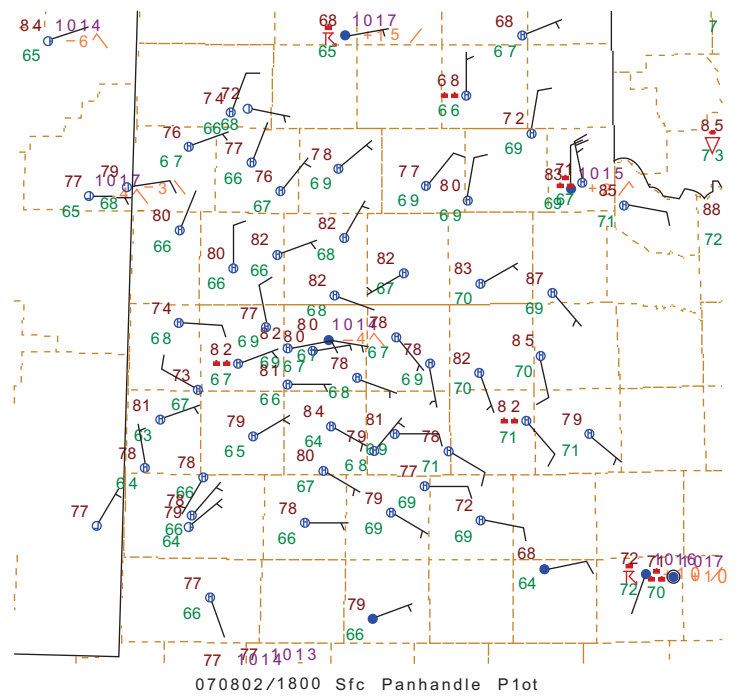

Fig. (1). A sample plot of WTM surface tower observations.

As described by Schroeder et al. [8], robust quality control (QC) procedures for the WTM data have been developed. In developing a QC algorithm, care is taken to remove the erroneous data while maintaining the integrity of the valid data as much as possible. The first step in the QC procedure is to replace any missing data with interpolation from the nearest two data points. Small sub-sets of the time series are examined to identify spikes in the data. This is done by moving a 7-point data window through the data, computing mean and standard deviation data for that window, and looking for data points that are significantly out of line with the statistics. The filtering pass is done three times to remove the anomalies. These procedures work very well at removing bad data while not altering the valid data points. It is important to note that the filtering process does not smooth or average out the time series, it only looks for and corrects spurious data points.

\section{ACARS}

These data are routed by several cooperating airlines to NOAA GSD (Global Systems Division) for quality control. General information about ACARS and how to access the data sets can be found on the website http://acweb.fsl.noaa. gov. ACARS wind and temperature data are collected by many commercial aircraft during both en route and ascent/descent modes of their flights at a very high frequency. At flight altitudes of about $23,000 \mathrm{ft}$, data are generally taken every 5-6 minutes. Nearer to airports the data spacing is decreased by some airlines. Below 18,000 ft, a vertical resolution of 1000 to $2000 \mathrm{ft}$. is quite common. More than 150 aircrafts provide data with a vertical resolution of $300 \mathrm{ft}$. during the first minute after take-off. The temporal and spatial distribution of the data is such that ACARS can provide valuable up-to-date weather data for short-range forecasts of atmospheric boundary layer winds.

The quality of ACARS data had been examined by many researchers $[2,9,10]$. Estimated wind vector accuracy was about $1.8 \mathrm{~m} / \mathrm{s}$ and estimated temperature accuracy was about $0.5^{\circ} \mathrm{C}$. When ACARS was compared to radiosondes, root mean square (RMS) deviations were 7.4 degrees in direction and $5.3 \mathrm{~m} / \mathrm{s}$ in speed. In comparing just the ACARS ascent/descent winds and temperatures with radiosondes, it was found that temperature differences were less than $2^{\circ} \mathrm{C}$ on 94 percent of all occasions, and less than $1^{\circ} \mathrm{C}$ greater than 68 percent of the time. Wind speed RMS deviations were 4.1 $\mathrm{m} / \mathrm{s}$, while direction RMS differences were 35 degrees (mostly due to light and variable wind situations).

\section{MM5/FDDA EXPERIMENTS}

MM5 provides various options for parameterizing precipitation and BL physics. The following BL-related physical parameterization options were selected for the simulation experiments.

- $\quad$ Grell moist-convection [11].

- Atmospheric radiation with the effects of clouds [12]

- $\quad$ MRF [13] planetary boundary layer

- $\quad$ Surface heat and moisture fluxes from the ground

- Surface energy budget to calculate the ground temperature

\section{- Multi-layer soil thermal diffusion}

We experimented with various nesting configurations in MM5 including one-, two-, and three-grid nest runs in conjunction with horizontal grid spacings ranging from $3 \mathrm{~km}$ to $20 \mathrm{~km}$. The model appeared to be quite reliable and robust in all nesting configurations. A close examination of the model output did not reveal any indication of computational instability during the model integrations. The results of just the single-nest (20 km grid spacing) FDDA simulations for the following three case studies are presented in this paper.

(A) 23 November 2002: Tranquil synoptic conditions.

(B) 21-22 February 2003: Weak synoptic disturbance with light precipitation.

(C) 8-9 May 2005: Severe thunderstorm outbreak in Central Texas 


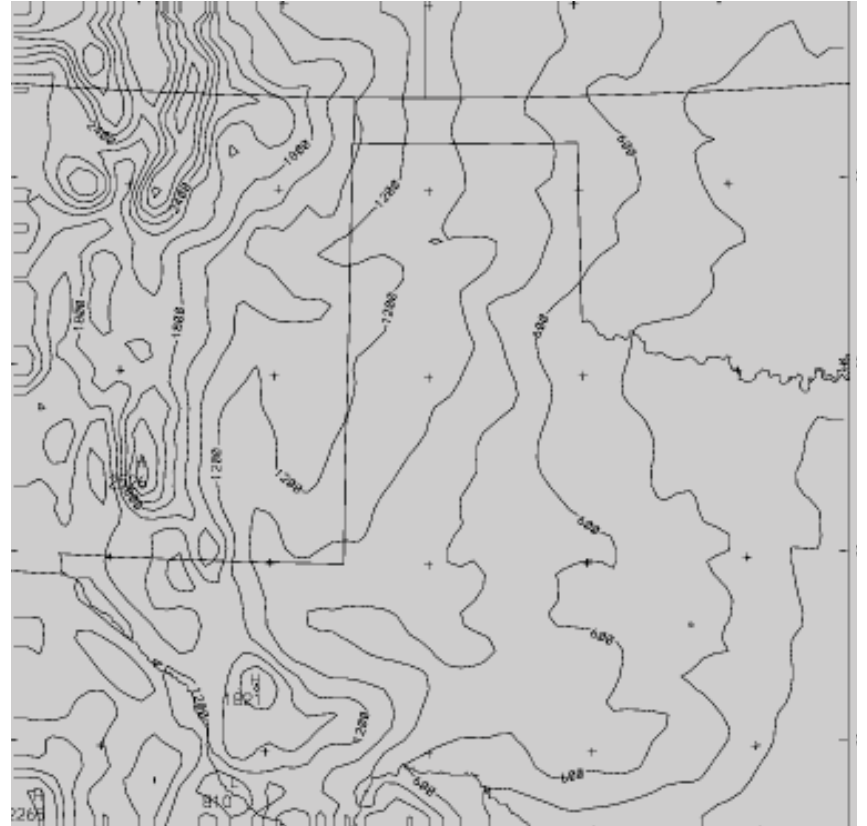

Fig. (2). MM5 model domain and terrain.

The version of the MM5 model used in the FDDA experiments is non-hydrostatic and has 24 terrain following $\sigma$ levels in the vertical. Other key model parameters are presented in Table 1. Fig. (2) shows the MM5 domain and terrain with WTM data for Cases A and B. Note that WTM (Fig. 1) situated in the middle of the domain encompasses roughly one tenth of the total area. The MM5 initial and lateral boundary conditions were derived from the NWS/NCEP Eta model [14], which had 50 vertical levels and a horizontal grid mesh size of $22 \mathrm{~km}$. All model integrations were performed on a SGI Octane-2 workstation.

Table 1. Key Case Study Parameters

\begin{tabular}{|c|c|c|c|c|}
\hline Case & $\begin{array}{c}\text { Horizontal } \\
\text { Dimension }\end{array}$ & $\boldsymbol{\sigma}$ Level & Grid Size & $\begin{array}{c}\text { Length of } \\
\text { Integration }\end{array}$ \\
\hline \hline A & 67 by 67 & 24 & $15 \mathrm{~km}$ & $24 \mathrm{~h}$ \\
\hline B & 67 by 67 & 24 & $15 \mathrm{~km}$ & $24 \mathrm{~h}$ \\
\hline C & 67 by 67 & 24 & $20 \mathrm{~km}$ & $36 \mathrm{~h}$ \\
\hline
\end{tabular}

\begin{tabular}{|c|c|c|}
\hline Case & $\begin{array}{c}\text { Starting Time } \\
\text { UTC/Day/Month }\end{array}$ & $\begin{array}{c}\text { Data Source/ } \\
\text { FDDA Period }\end{array}$ \\
\hline \hline A & $00 / 23 / 11$ & WTM $/ 6$ to $12 \mathrm{~h}$ \\
\hline B & $00 / 21 / 02$ & WTM $/ 6$ to $12 \mathrm{~h}$ \\
\hline $\mathrm{C}$ & $00 / 08 / 05$ & ACARS $/ 12$ to $24 \mathrm{~h}$ \\
\hline
\end{tabular}

\section{FDDA WITH WTM DATA}

The observational nudging package provided by MM5 is used in the FDDA experiments. The details of the MM5 observational nudging scheme can be found in the NCAR report [5]. The nudging parameters selected in this study are as follows:
- Nudging factors $(\mathrm{N})$ for wind, temperature, and humidity is $4 \times 10^{-4} \mathrm{~s}^{-1}$.

- Horizontal radius of influence (R) is $100 \mathrm{~km}$ from the observation site.

- Vertical radius of influence $(\Delta \sigma)$ is 0.001 centered at the level of $\sigma=0.995$.

- $\quad$ Time window $(\Delta \mathrm{t})$ is 60 min centered at the observation time.

In each case, the MM5 simulations included a 24-h control run (CNTR) without invoking the WTM data along with a similar 24-h FDDA run with observational nudging between $6 \mathrm{~h}$ and $12 \mathrm{~h}$ model time. In the CNTR run, MM5 reproduced the observed surface flow in Case A quite well, while in Case B the model over-predicted the surface wind speeds but did well in surface temperature and dew point forecasting [15].

Figs. (3) and (4) show separately the $12 \mathrm{~h}$ and $18 \mathrm{~h}$ simulated vector wind and temperature $(\mathrm{T})$ differences (CNTRFDDA) at $\sigma=0.97$ in Case A. As expected, at the end of FDDA the most notable differences occur in the general area of the WTM. The largest differences are over $2 \mathrm{~m} / \mathrm{s}$ in wind speed and $0.8^{\circ} \mathrm{C}$ in $\mathrm{T}$. However, these differences dissipate rapidly after FDDA is turned off. In 6 hours (18 UTC) the maximum differences on the grid have dropped to less than $0.6 \mathrm{~m} / \mathrm{s}$ and about $0.1^{\circ} \mathrm{C}$, along the eastern edge of the WTM domain. An eastward translation of the vector wind differences is noted between 1200 and 1800 UTC. Increasing the length of FDDA to $9 \mathrm{~h}$ (from $3 \mathrm{~h}$ to $12 \mathrm{~h}$ ) resulted in very similar 24-h simulations.

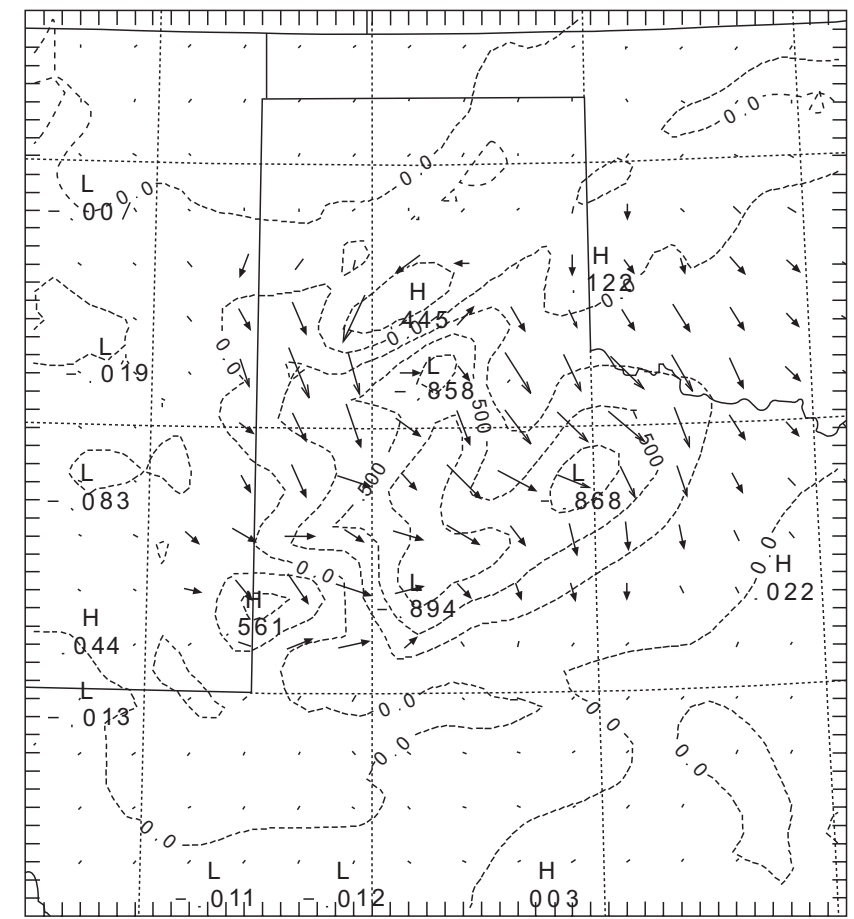

Fig. (3). Vector wind and T differences (CNTR-FDDA) at $\sigma=0.97$ ( $\sim 20 \mathrm{~m}$ above the surface) for Case A at 12 UTC, 23 Nov. 2002. The contour interval for $\mathrm{T}$ is $0.25^{\circ} \mathrm{C}$. 


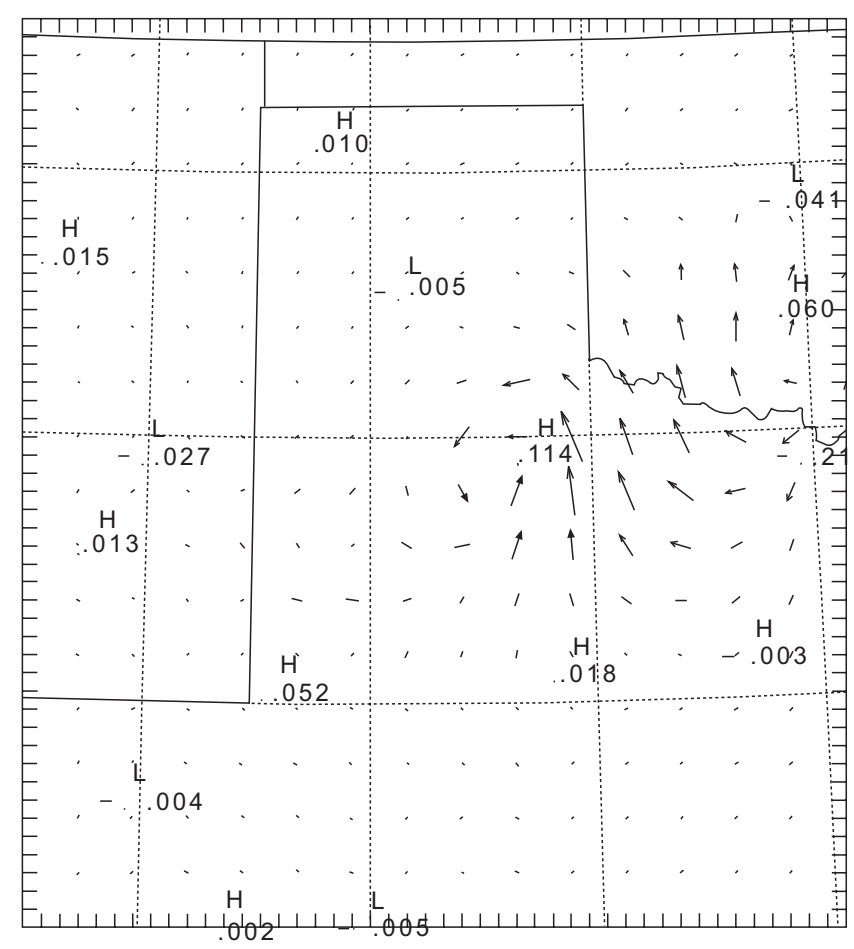

Fig. (4). Similar to Fig. (2) but at 18 UTC 23 Nov. 2002.

Table 2 shows the means (M) and standard deviations (SD) of the $\mathrm{u}, \mathrm{v}$, and $\mathrm{T}$ differences computed over the model domain as a function of time for both the surface and lowertroposphere at $\sigma=0.68(\approx 700 \mathrm{hPa})$ and for Case A. At both levels, all means and SDs are zero at $3 \mathrm{~h}$. At the surface, the means show mild temporal oscillations, while the SDs rise rapidly at $6 \mathrm{~h}$ and then drop sharply in 6 hours (becoming quite small at $18 \mathrm{~h}$ ). The maximum differences in surface SDs occurring at the end of data insertion (12 h) are one order of magnitude larger than their upper-level counterparts occurring around $18 \mathrm{~h}$. The effect due to inserting WTM surface data on the upper-level flow is clearly negligible, and the effect on the surface flow diminishes within a few hours after the termination of FDDA. Similar results for Case B are noted in Table 3. The surface means and SDs have comparable sizes as in Table $\mathbf{2 a}$, although the $\mathrm{SD}$ of $\mathrm{T}$ reaches its maximum a little later. In both cases, results suggest that FDDA with the WTM surface observations had very little impact on the model's performance beyond the first few hours.

\section{FDDA WITH ACARS DATA}

The severe weather case of 5-6 May 2005 (Case C) was selected for the FDDA using ACARS experiments. The model domain was similar to that shown in Fig. (2) except covering a larger area. First, we carried out a 36-h simulation of the severe weather environment which included a dryline perturbation in West Texas and intense convection in Central Texas from 1200 UTC to 0000 UTC of 8- 9 May. Again, this simulation without FDDA was regarded as the control run (CNTR) to provide a benchmark for evaluating the impact of ACARS data. In the subsequent FDDA runs, more than 90 ACARS profiles over an area across several mountain and south central states were processed for use in the MM5 ob- servational nudging. The nudging parameters were similar to those mentioned earlier. However, some adjustments were made in order to test the sensitivity of the model's response to changes in the nudging parameters and data density.

Table 2. Mean (M) and Standard Deviation (SD) of $u$, $v$, and T Differences (CNTR - FDDA) Over the Model Domain for Case $A$ at Every 3 Hours at (a) Surface and (b) $\sigma=0.68(p \approx 700 \mathrm{hPa})$

Table 2a. Surface

\begin{tabular}{|c|c|c|c|c|c|c|}
\hline \multirow{2}{*}{$\mathbf{t}(\mathbf{h})$} & \multicolumn{2}{|c|}{$\mathbf{u}(\mathbf{m} / \mathbf{s})$} & \multicolumn{2}{|c|}{$\mathbf{v}(\mathbf{m} / \mathbf{s})$} & \multicolumn{2}{|c|}{$\left.\mathbf{T}{ }^{\circ} \mathbf{C}\right)$} \\
\cline { 2 - 7 } & $\mathbf{M}$ & $\mathbf{S D}$ & $\mathbf{M}$ & $\mathbf{S D}$ & $\mathbf{M}$ & $\mathbf{S D}$ \\
\hline \hline 6 & -0.05 & 0.17 & -0.02 & 0.09 & 0.00 & 0.01 \\
\hline 9 & -0.11 & 0.34 & 0.01 & 0.13 & 0.00 & 0.07 \\
\hline 12 & -0.09 & 0.32 & 0.09 & 0.31 & 0.00 & 0.05 \\
\hline 15 & 0.01 & 0.08 & 0.03 & 0.09 & 0.00 & 0.05 \\
\hline 18 & 0.01 & 0.04 & 0.00 & 0.06 & 0.00 & 0.03 \\
\hline 21 & 0.00 & 0.02 & -0.01 & 0.03 & 0.00 & 0.02 \\
\hline 24 & 0.00 & 0.03 & 0.00 & 0.03 & 0.00 & 0.02 \\
\hline
\end{tabular}

Table 2b. $\sigma=0.68$

\begin{tabular}{|c|c|c|c|c|c|c|}
\hline \multirow{2}{*}{$\mathbf{t}(\mathbf{h})$} & \multicolumn{2}{|c|}{$\mathbf{u}(\mathbf{m} / \mathbf{s})$} & \multicolumn{2}{|c|}{$\mathbf{v}(\mathbf{m} / \mathbf{s})$} & \multicolumn{2}{c|}{$\mathbf{T}\left({ }^{\circ} \mathbf{C}\right)$} \\
\cline { 2 - 7 } & $\mathbf{M}$ & $\mathbf{S D}$ & $\mathbf{M}$ & $\mathbf{S D}$ & $\mathbf{M}$ & $\mathbf{S D}$ \\
\hline \hline 6 & 0.00 & 0.00 & 0.00 & 0.00 & 0.00 & 0.00 \\
\hline 9 & 0.00 & 0.01 & 0.00 & 0.01 & 0.00 & 0.00 \\
\hline 12 & 0.00 & 0.02 & 0.00 & 0.02 & 0.00 & 0.01 \\
\hline 15 & 0.00 & 0.03 & 0.00 & 0.03 & 0.00 & 0.01 \\
\hline 18 & 0.00 & 0.03 & 0.00 & 0.04 & 0.00 & 0.01 \\
\hline 21 & 0.00 & 0.03 & 0.01 & 0.04 & 0.00 & 0.01 \\
\hline 24 & 0.00 & 0.02 & 0.00 & 0.02 & 0.00 & 0.01 \\
\hline
\end{tabular}

Table 3. Similar to Table 2a but for Case B

\begin{tabular}{|c|c|c|c|c|c|c|}
\hline \multirow{2}{*}{$\mathbf{t}(\mathbf{h})$} & \multicolumn{2}{|c|}{$\mathbf{u}(\mathbf{m} / \mathbf{s})$} & \multicolumn{2}{c|}{$\mathbf{v}(\mathbf{m} / \mathbf{s})$} & \multicolumn{2}{c|}{$\mathbf{T}\left({ }^{\circ} \mathbf{C}\right)$} \\
\cline { 2 - 7 } & $\mathbf{M}$ & $\mathbf{S D}$ & $\mathbf{M}$ & $\mathbf{S D}$ & $\mathbf{M}$ & $\mathbf{S D}$ \\
\hline \hline 6 & -0.01 & 0.05 & 0.02 & 0.09 & 0.00 & 0.00 \\
\hline 9 & 0.03 & 0.14 & 0.06 & 0.21 & 0.00 & 0.02 \\
\hline 12 & 0.03 & 0.15 & 0.05 & 0.20 & 0.00 & 0.03 \\
\hline 15 & 0.02 & 0.07 & 0.00 & 0.05 & 0.00 & 0.04 \\
\hline 18 & 0.00 & 0.06 & -0.01 & 0.06 & 0.01 & 0.09 \\
\hline 21 & 0.00 & 0.05 & 0.00 & 0.05 & 0.00 & 0.05 \\
\hline 24 & 0.00 & 0.06 & 0.00 & 0.06 & 0.00 & 0.04 \\
\hline
\end{tabular}

The distribution of the ACARS data used in this case study is shown in Fig. (5). In the lower and middle MM5 
(a)

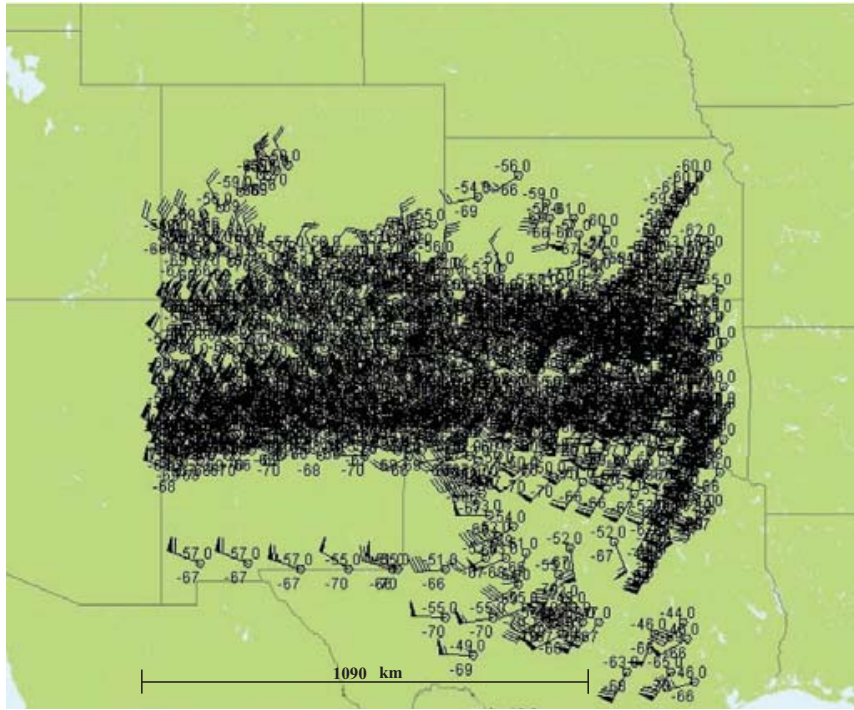

(b)

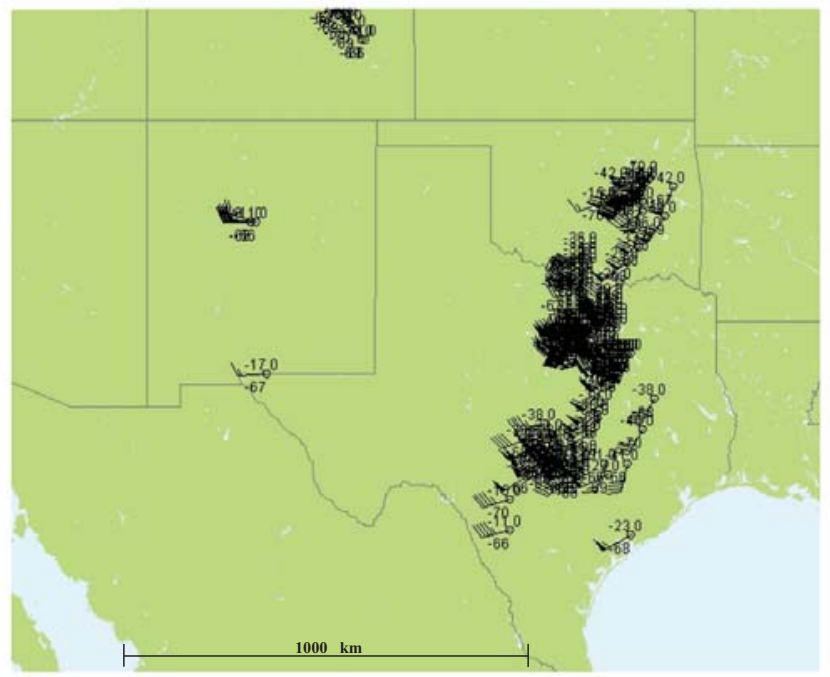

(c)

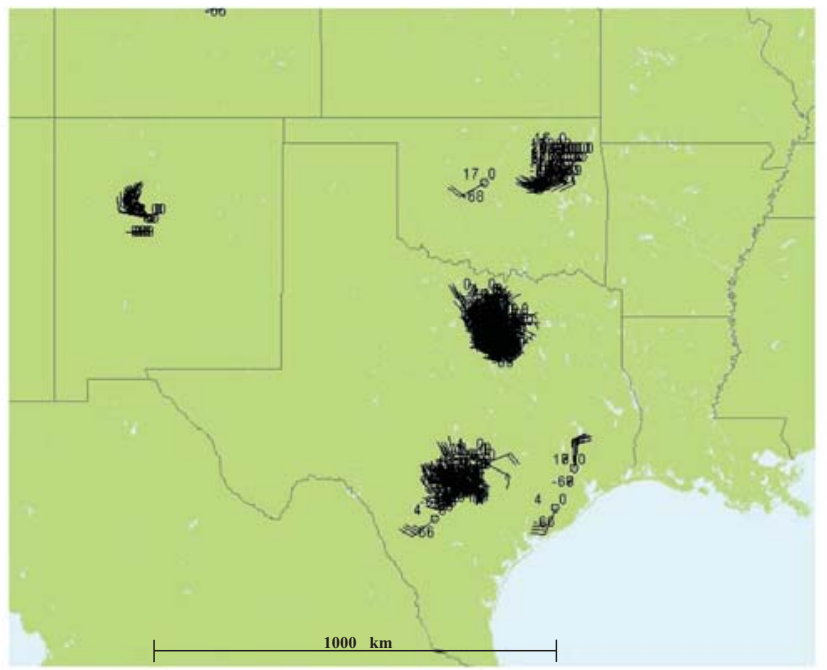

Fig. (5). ACARS observation sites, 12 UTC, 8 to 00 UTC, 9 May 2005: (a) upper model layers centered at $300 \mathrm{hPa}$, (b) middle model layers centered at $500 \mathrm{hPa}$, and (c) lower model layers centered at $700 \mathrm{hPa}$. model layers clusters of ACARS reports oriented in the north-south direction are found throughout central Texas and Oklahoma. The data coverage spreads more uniformly in the upper model layers. Each data point recorded during a flight at a given time, latitude and longitude, and altitude is treated as one single independent observation. The locations of individual observations in terms of the model grid system must first be determined, and they are then organized in order of increasing time as required by the MM5 nudging program. Explanations for the input data structure can be found in the MM5 tutorial notes under the section of "Data Used in FDDA" [5].

The ACARS observations used in the case study initially consisted of 1928 data points. The number dropped to 1213 after averaging observations within the same proximity, meaning that they were reported in the same time slot and at the same vertical level while within $10 \mathrm{~km}$ (half the grid size) of the individual model grid points. Many more observations were inserted in the model upper layers than in the middle and lower layers. The first FDDA experiment (E1) was a 36 -h run with 12-h observational nudging applied between the $12 \mathrm{~h}$ and $24 \mathrm{~h}$ model integration periods, and based on the averaged ACARS data set. The nudging parameters as defined earlier were $\mathrm{R}=100 \mathrm{~km}, \mathrm{~N}=4 \times 10^{-4} \mathrm{~s}^{-1}, \Delta \sigma=$ 0.001 , but with $\Delta \mathrm{t}=30 \mathrm{~min}$.

The three additional experiments conducted to test the model's response to changes in $\mathrm{R}, \mathrm{N}$, and data density were:

- $\quad \mathrm{E} 2$ similar to $\mathrm{E} 1$ but $\mathrm{R}=50 \mathrm{~km}$.

- $\quad$ E3 similar to E1 but $\mathrm{N}=2 \times 10^{-4} \mathrm{~s}^{-1}$.

- E4 similar to E1 but with all 1928 data points or without the averaging procedure.

\section{a. CNTR vs E1}

Figs. (6) and (7) show the MM5 initial state (00 UTC 8 May) at both the surface and $700 \mathrm{hPa}$, respectively. A northsouth oriented dryline is evident in the middle of the model domain. The major features at the surface are southerly flow to the east of the dryline and southwesterly flow to the west (near the Texas-New Mexico state line), creating a confluence of air near the dryline. Notable changes in the wind directions from southerly at the surface to westerly at 700 $\mathrm{hPa}$ (veering profile) occur in South Texas. The $700 \mathrm{hPa}$ confluent zone is located in Central Texas and Oklahoma, which was well to the east of the dryline, and there is a counter-clockwise turning of $700 \mathrm{hPa}$ winds from westerly to southerly in the eastern half of Texas where the outbreak of severe weather was observed later. The average wind speed at $700 \mathrm{hPa}$ is on the order of $10 \mathrm{~m} / \mathrm{s}$, while at $300 \mathrm{hPa}$ (not shown) the flow is predominantly southwesterly with a relatively narrow zone of winds in excess of $30 \mathrm{~m} / \mathrm{s}$ stretching from Mexico to the northern boundary of the modeling domain. This stronger zone of $300 \mathrm{hPa}$ flow generally occurs in the vicinity of the dryline.

Fig. (8) shows the observed surface vector winds and $T_{d}$ at 12 UTC 9 May. Throughout the 36-h period, southerly flow persists across Central Texas and continues to advect 
(a)

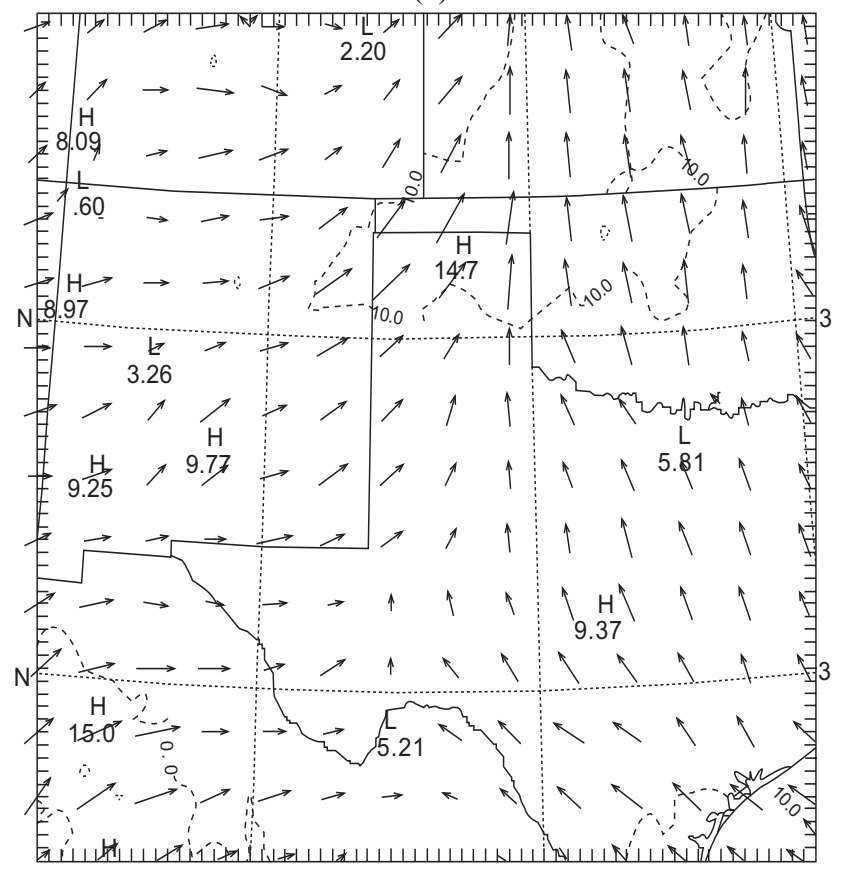

(b)

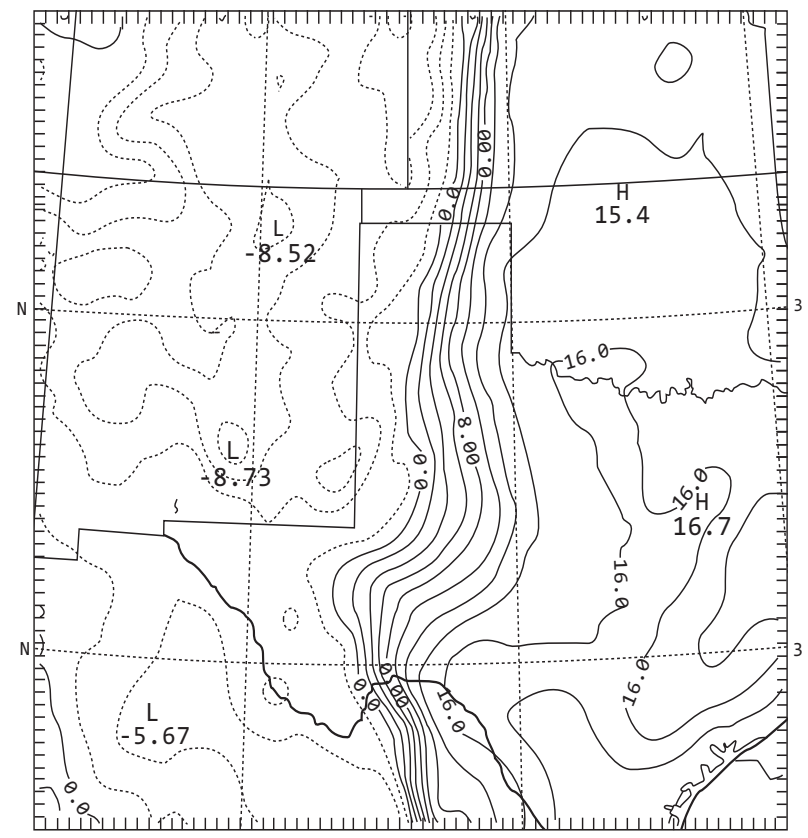

Fig. (6). MM5 Initial state (a) vector winds $(\mathrm{m} / \mathrm{s})$ and $(\mathbf{b}) \mathrm{T}_{\mathrm{d}}\left({ }^{\circ} \mathrm{C}\right)$ at the surface.

moist air from the Gulf of Mexico inland. The $T_{d}$ gradients along the dry line in West Texas tighten, although they do weaken considerably in the Panhandle. The result is a double boundary surface $T_{d}$ structure enclosing a diffluence area of relatively weak surface winds. Again, there is confluence associated with the dryline. Significant changes take place in the upper-air flow patterns (not shown). At $700 \mathrm{hPa}$, the counter-clockwise turning flow (Fig. 7) $12 \mathrm{~h}$ earlier is replaced by a clockwise cyclonic turning with southerly flow in South-Central Texas transitioning to westerly in East Texas. At $300 \mathrm{hPa}$ a westerly flow regime dominates the whole area with no upper-air jet features appearing in the model domain during this time.

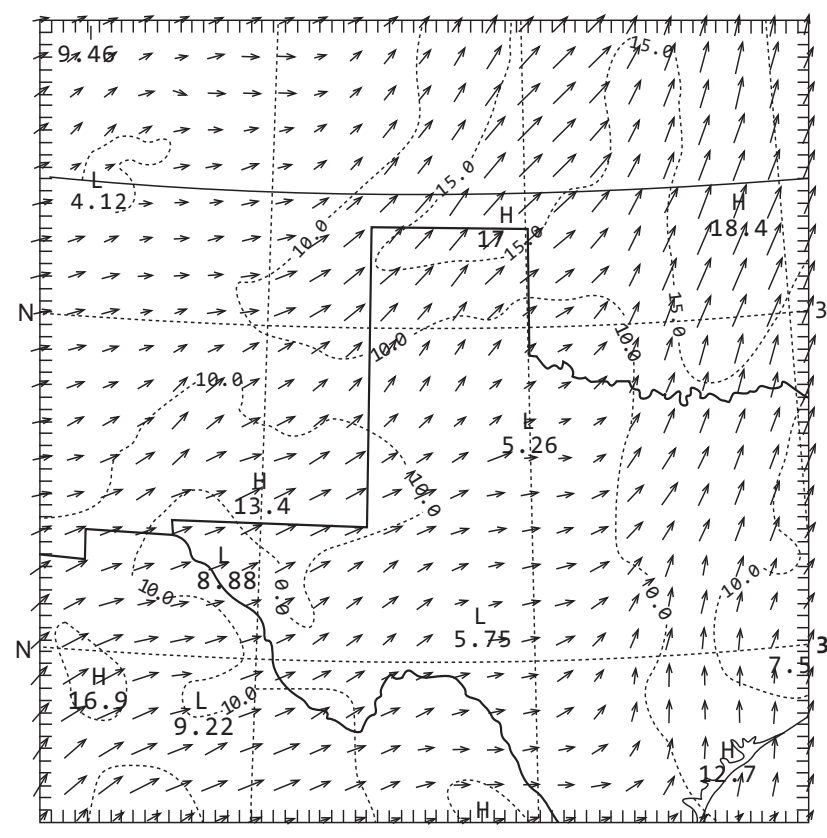

Fig. (7). MM5 Initial $700 \mathrm{hPa}$ vector winds. The contour interval is $10 \mathrm{~m} / \mathrm{s}$.

Figs. (9) and (10) show 24-h and 36-h simulated surface winds and $T_{d}$ from the CNTR run, respectively. Throughout the first $24 \mathrm{~h}$, a significant weakening of surface circulation occurred in the western half of the domain. The MM5 predicted a large increase in the $T_{d}$ gradients in West Texas, and a northeastward intrusion of dry air and resulting dryline bulging into regions of western Kansas and the Oklahoma Panhandle. At $36 \mathrm{~h}$, the middle section of the dryline retreated slightly westward and aligned along the Texas-New Mexico border. The observed double-boundary structure (Fig. 8) and tight $T_{d}$ gradients were well predicted, but the model dryline in the area of the Texas Panhandle was predicted too far to the west. This was likely related to the MM5 over-prediction of southerly flow in this region, which caused an advection of moister air further northwestward into the Texas Panhandle. Clearly, surface convergence played a key role in the intensification and maintenance of the sharp $T_{d}$ gradients.

The model convective precipitation rates (not shown) in the CNTR run reveal that no organized convection takes place before $18 \mathrm{~h}$, and that convection in Oklahoma and West Texas (along the eastern edge of the dryline) took place from $18 \mathrm{~h}$ to $30 \mathrm{~h}$. However, no convection was present near the dryline at $36 \mathrm{~h}$. The major convective activity was found quite a distance from the dryline in Central and East Texas, where severe weather was reported. The observed convective activity reached its peak intensity around $24 \mathrm{~h}$, and tailed off over the next $12 \mathrm{~h}$.

Fig. (11) shows the MM5 simulated 24-h and 36-h accumulated precipitation. At $36 \mathrm{~h}$, some negative impacts of the eastern grid boundary on the model precipitation field are noted. Fig. (12) shows the observed 24-h accumulated precipitation ending at $12 \mathrm{~h}$ (1200 UTC 8) and $36 \mathrm{~h}$ (1200 UTC 9) of the model integration. The general patterns of the $24-\mathrm{h}$ simulation compare quite well with the observations regarding the broad areas of heavy precipitation. 
(a)

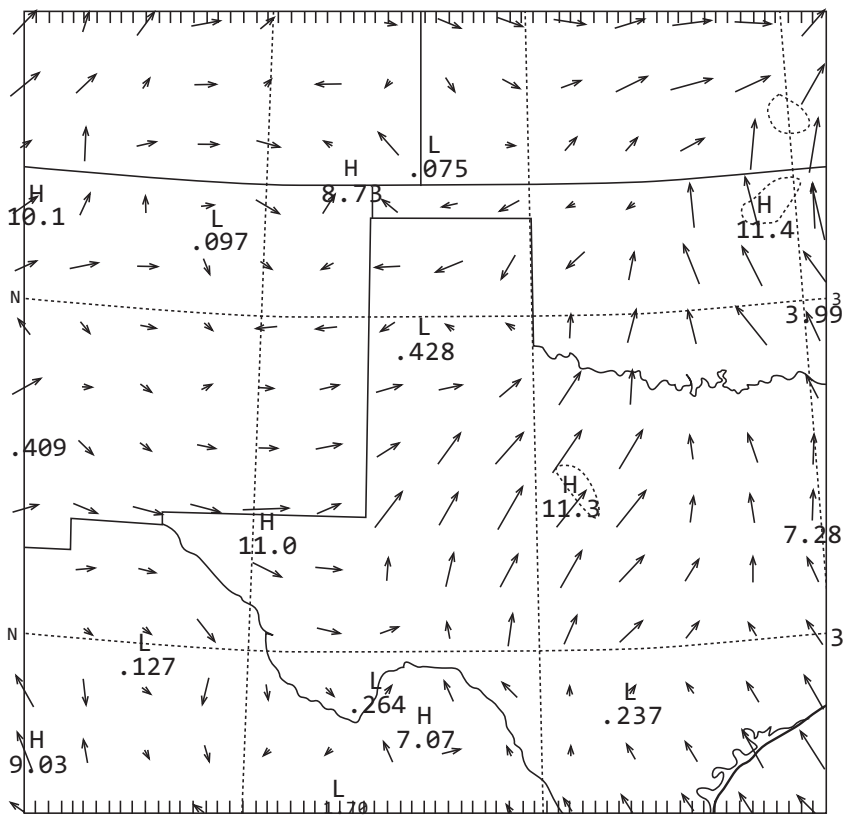

(b)

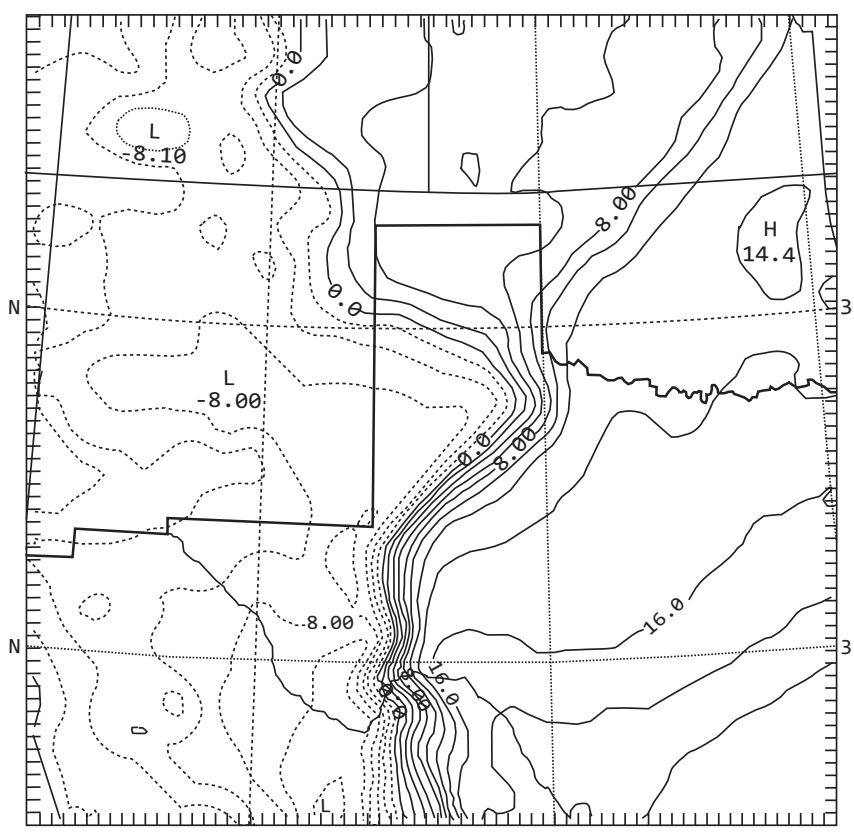

Fig. (8). Observed surface conditions at 12 UTC 9 May: (a) vector winds $(\mathrm{m} / \mathrm{s})$ and $(\mathbf{b}) \mathrm{T}_{\mathrm{d}}\left({ }^{\circ} \mathrm{C}\right)$.

Fig. (13) shows the E1 simulated $T_{d}$ at $36 \mathrm{~h}$. The large $T_{d}$ differences between CNTR and E1 occurred in West Texas and eastern New Mexico e.g., due to the modeled location and orientation of the dryline and surface confluence zone). Fig. (14) shows the 36-h simulated accumulated precipitation in E1. The overall patterns resemble those of CNTR (Fig. 11). However, some differences between the two runs are noted. In CNTR, an area of over $5 \mathrm{~cm}$ of rainfall is predicted in North Texas at $24 \mathrm{~h}$, while in E1 a similar maximum is centered further to the south. At $36 \mathrm{~h}$, basic features such as the location of heavy rainfall $(>2.5 \mathrm{~cm})$ in the Central Texas, appear to be in better agreement with the observations In E1 (Fig. 12) than in CNTR. (a)

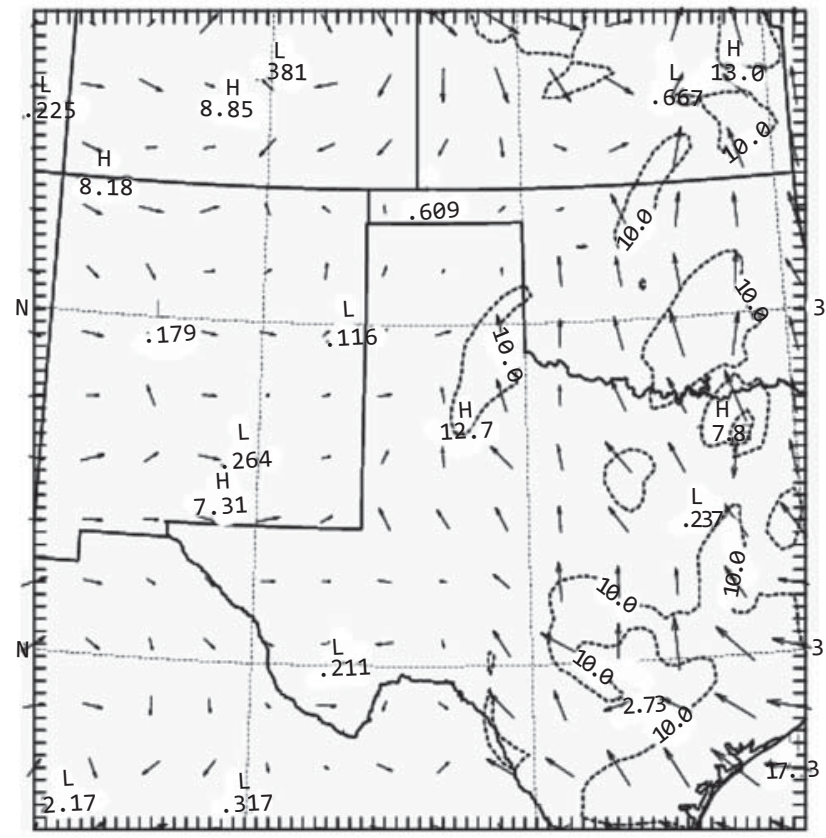

(b)

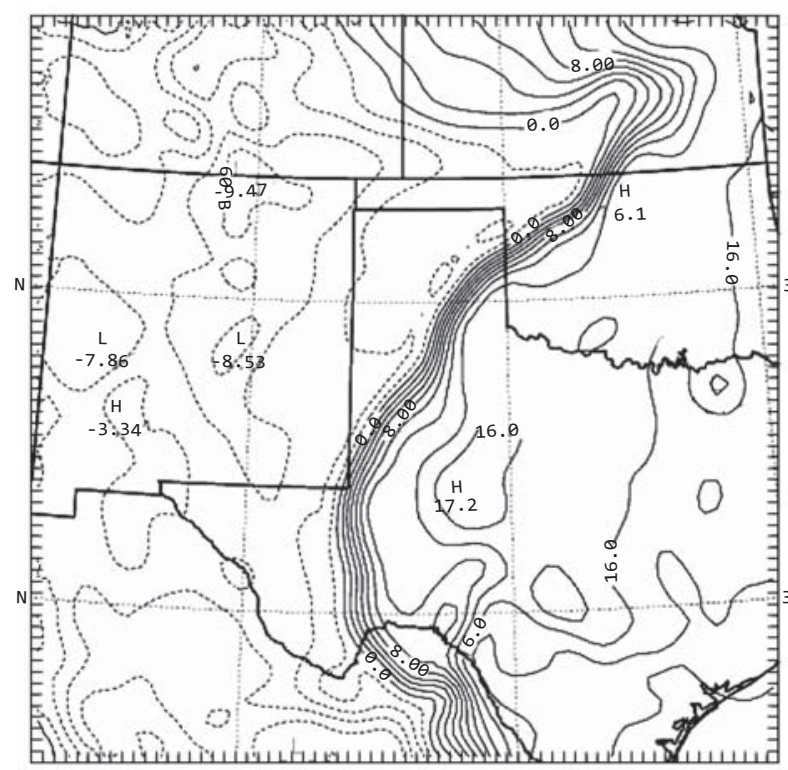

Fig. (9). $24 \mathrm{~h}$ simulated (a) surface winds (m/s) and (b) $\mathrm{T}_{\mathrm{d}}\left({ }^{\circ} \mathrm{C}\right)$.

Although the nudging of ACARS data ends at $24 \mathrm{~h}$, its impact on the MM5 simulations persists through the next 12 h. Fig. (15) shows the difference (CNTR-E1) maps of surface vector winds $(\Delta \mathrm{V})$, surface temperatures $(\Delta \mathrm{T})$, and specific humidity $(\Delta \mathrm{q})$ at $36 \mathrm{~h}$. Note that no $\mathrm{q}$ data were used in nudging. Clearly, $\Delta \mathrm{V}$ is compounded by latent heating. The locations of the $\Delta \mathrm{V}, \Delta \mathrm{T}$, and $\Delta \mathrm{q}$ centers are well correlated with each other at $24 \mathrm{~h}$, but not as well at $36 \mathrm{~h}$. At $24 \mathrm{~h}$, over $15 \mathrm{~m} / \mathrm{s} \Delta \mathrm{V}$ are found in many locations, and $\Delta \mathrm{T}$ and $\Delta \mathrm{q}$ reveal several maximum and minimum centers with values as large as $6^{\circ} \mathrm{C}$ and $7 \mathrm{gm} / \mathrm{kg}$ respectively dispersed across Texas and Oklahoma. Twelve hours later there still exist areas of large $\Delta \mathrm{V}$. However, we see clear fading of $\Delta \mathrm{T}$ 
(a)

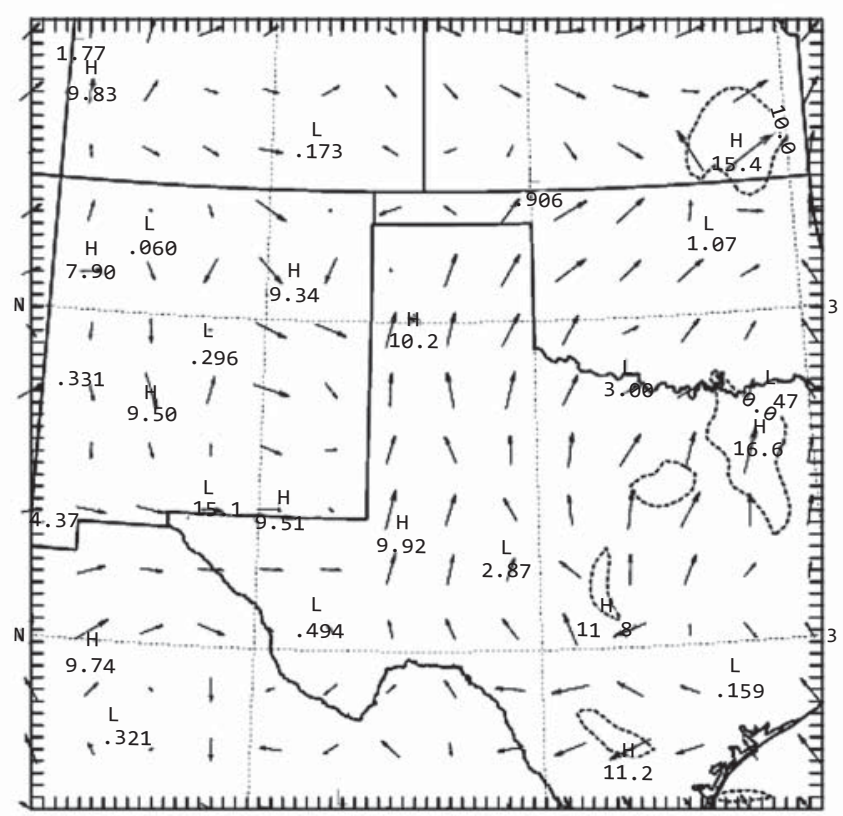

(b)

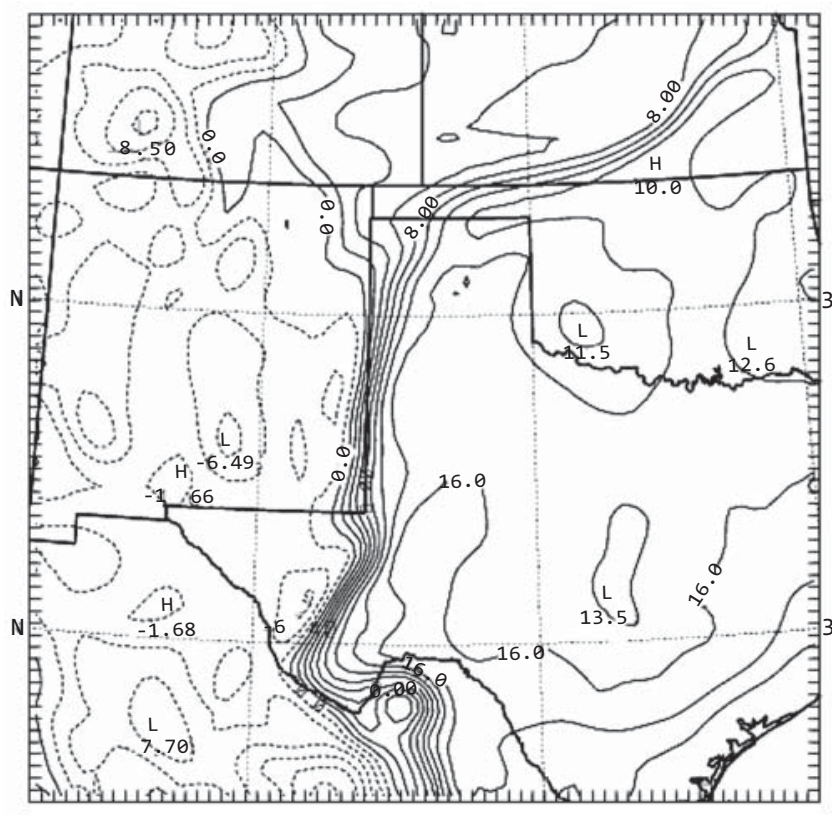

Fig. (10). As in Fig. (9), except for $36 \mathrm{~h}$.

during the $12-\mathrm{h}$ period. At $36 \mathrm{~h}$, the most pronounced $\Delta \mathrm{q}$ are found in the vicinities of the Kansas- Oklahoma and TexasNew Mexico state lines, likely due to the discrepancy in the model's predicted location and orientation of the dryline.

Fig. (16) shows (CNTR-E1) and (E1-CNTR) in the 36-h accumulated precipitation $(\Delta \mathrm{P})$. The CNTR run produces a broad area of much higher rainfall in North Texas with the largest $\Delta \mathrm{P}$ over 5 inches, and smaller areas of positive $\Delta \mathrm{P}$ further south. The E1 simulation produces significantly heavier rainfall in the Central Texas. The observed patterns in Fig. (12) appear to support the high positive (E1-CNTR) $\Delta \mathrm{P}$ in Texas, in addition to the area of positive $\Delta \mathrm{P}$ in the vicinity of the Oklahoma-Texas border. The bulk of $\Delta \mathrm{P}$ between E1 and CNTR occurs throughout the final $12 \mathrm{~h}$ of the model simulation period, indicating significant influences of ACARS data on the model precipitation processes many hours after the "turning off" of FDDA.

(a)

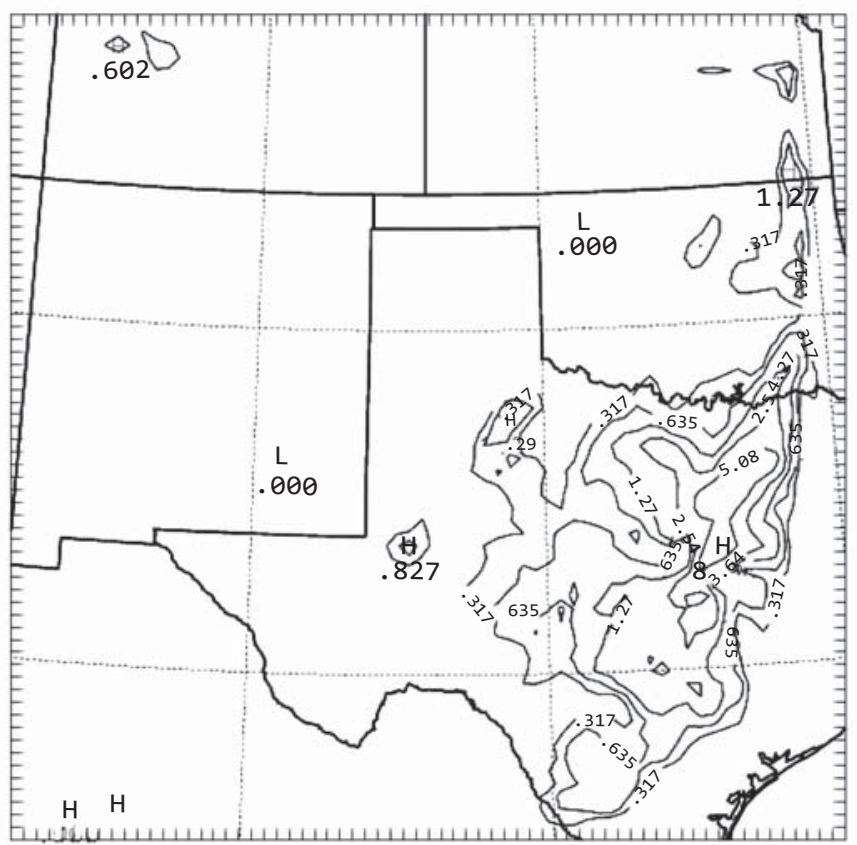

(b)

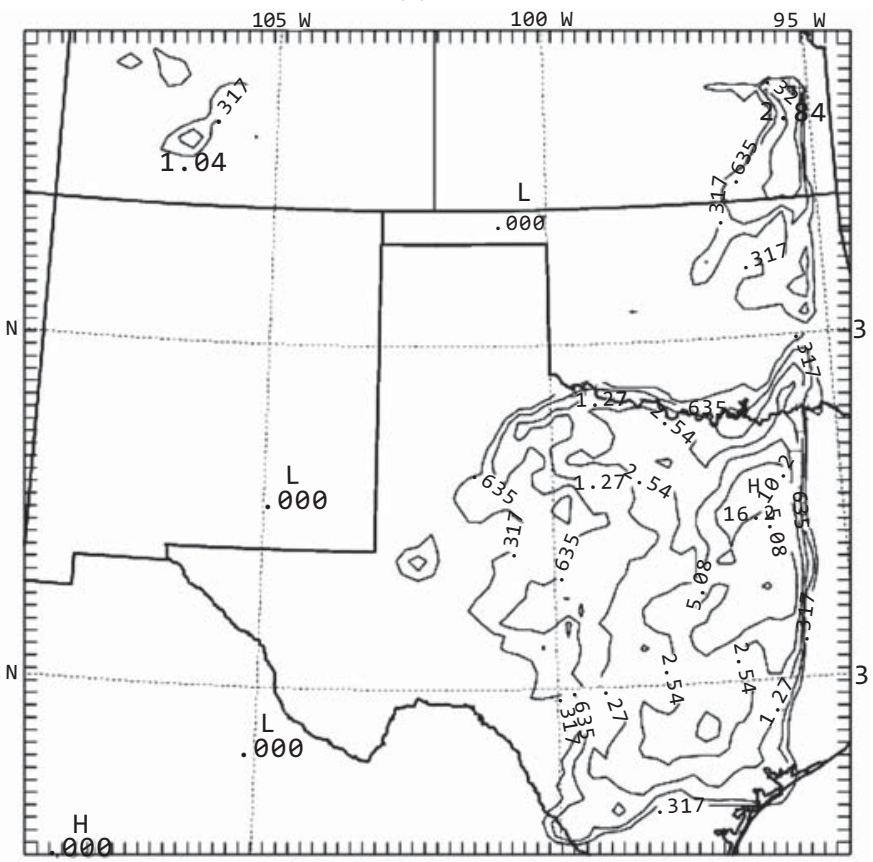

Fig. (11). (a) $24 \mathrm{~h}$ and (b) $36 \mathrm{~h}$ accumulated precipitation (cm) for the CNTR run.

Table 4 summarizes time sequences of means and SDs of the (CNTR-E1) differences in $\mathrm{u}, \mathrm{v}, \mathrm{T}$, and q over the model domain at the (i) surface, (ii) lower-troposphere $(\sigma=0.68)$, and iii) upper troposphere $(\sigma=0.32)$ for Case $C$. The basic structure of means and SDs at all levels is rather similar. 
(a)

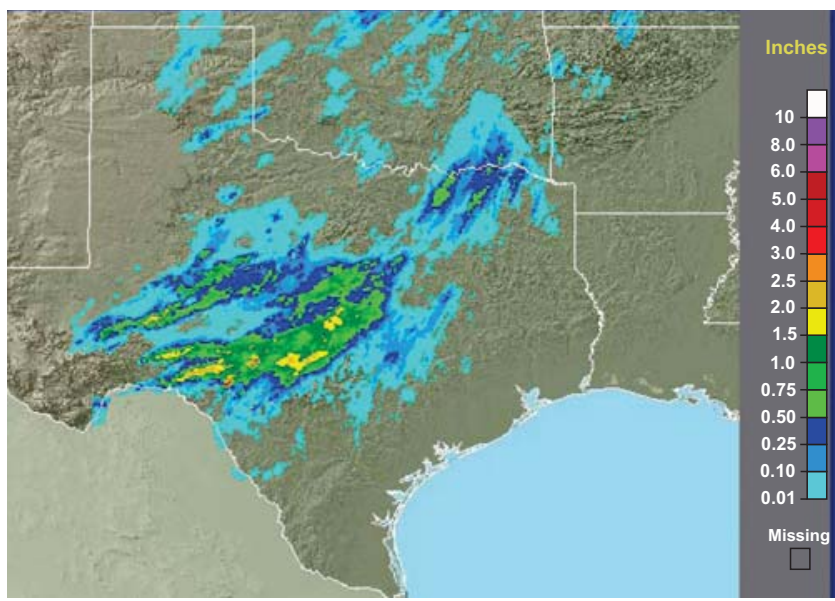

(b)

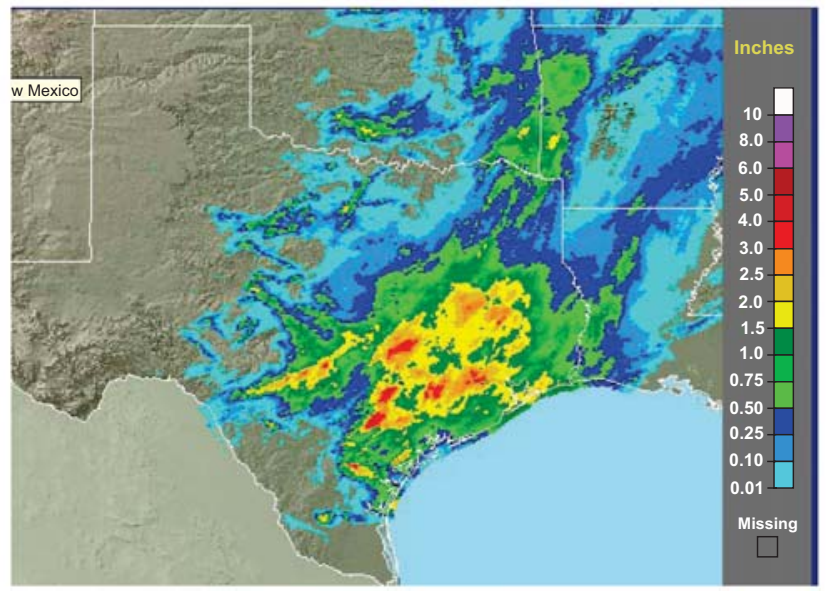

Fig. (12). 24-h accumulated precipitation observed at (a) 1200 UTC, 8 and (b) 1200 UTC, 9 May 2005. (after www.srh.noaa.gov/ rfcshare/precip_analysis_new.php).

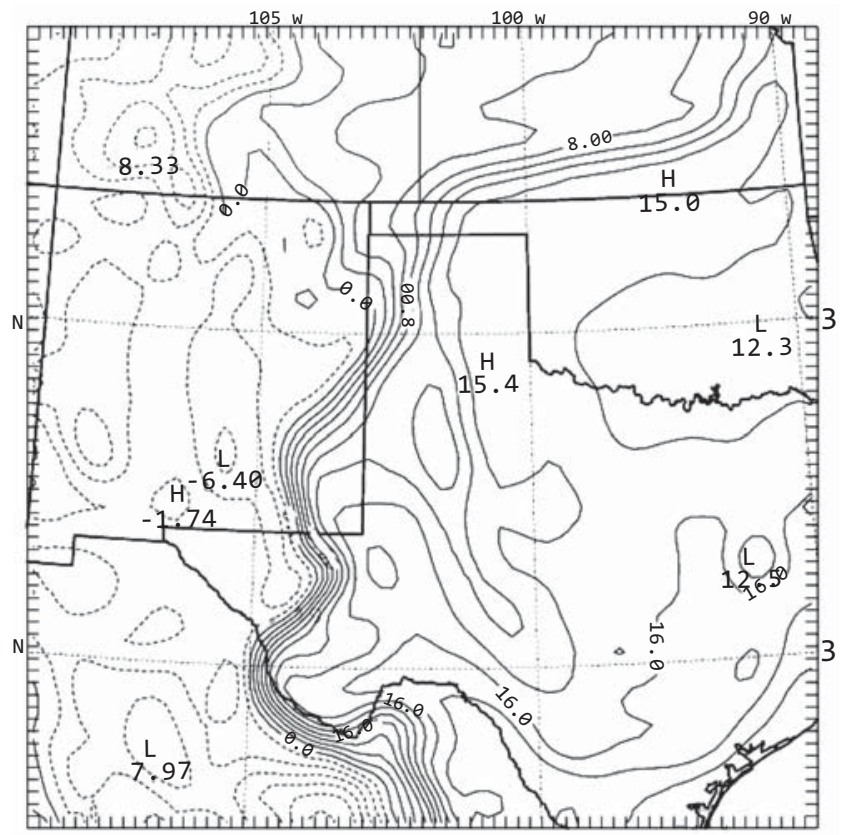

Fig. (13). $36 \mathrm{~h}$ simulated $\mathrm{T}_{\mathrm{d}}\left({ }^{\circ} \mathrm{C}\right)$ for $\mathrm{E} 1$.

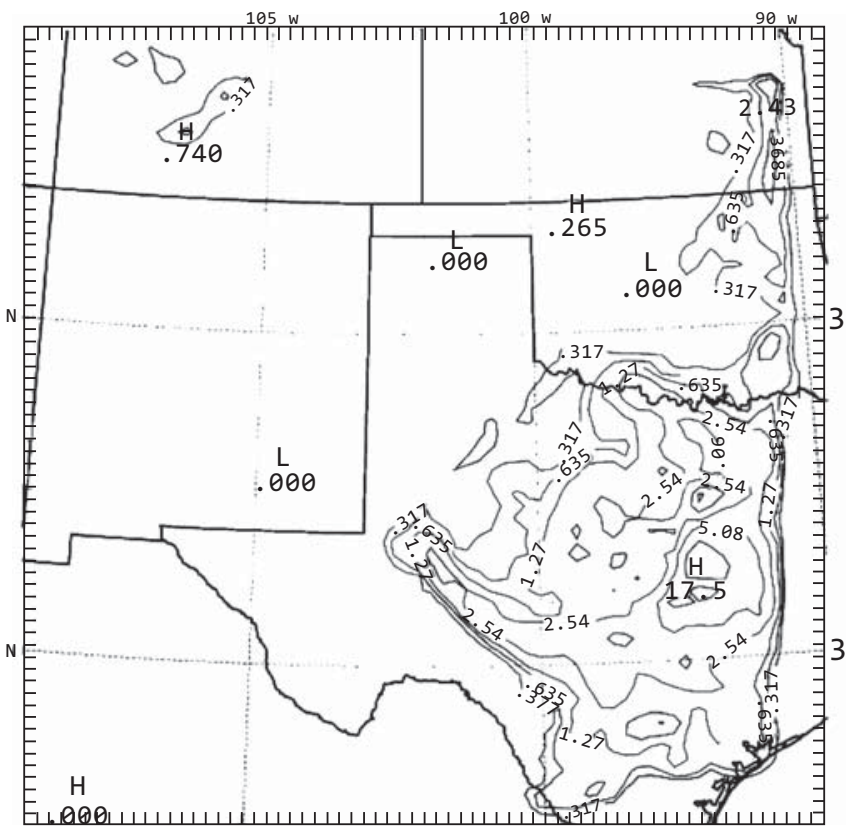

Fig. (14). As in Fig. (11b), except for E1.

Some oscillations are revealed in the mean values between $12 \mathrm{~h}$ and $36 \mathrm{~h}$ of the simulation period. The amplitudes are not particularly large, and there is no coherent relationship in the frequency and phase between any two variables or two levels. The SDs of $u, v$, and T increase rapidly after FDDA is invoked $12 \mathrm{~h}$ into the model simulation. The small but nonzero SDs of $\mathrm{u}, \mathrm{v}$, and $\mathrm{T}$ at $12 \mathrm{~h}$ are probably due to the use of the 60 -min time window centered at the starting point. For $\mathrm{q}$ there are no changes at $12 \mathrm{~h}$ and its SD values increase gradually before $21 \mathrm{~h}$ (because the ACARS profiles used do not include humidity data). The SDs at the individual levels reach their highest values after $24 \mathrm{~h}$, although at different times depending upon level and parameter.. It is interesting to note that more often these maximums occur a few hours after the termination of FDDA ( $24 \mathrm{~h}$ into the simulation). Also, at the end of simulations, all SDs remain quite high and close to those noted at $24 \mathrm{~h}$. It indicates that the model is able to retain the profile information even hours after ending FDDA. In contrast the model tends to forget quickly the inserted surface data as seen in the WTM experiments.

Table 4 shows that there are no significant differences in the SD values of $\mathrm{u}$ and $\mathrm{v}$ between the surface and upper levels. Considering that generally lower wind speeds exist near the surface, we may argue that the ACARS profiles have larger impact on air motion near the surface than in the upper levels. The close correlation between $\Delta \mathrm{V}$ and the model precipitation (Fig. 12) suggests that latent heating likely has an important role in defining SDs. For these experiments, the FDDA appears to result in a cooler and wetter lower and upper troposphere, while a warmer and drier middle troposphere (not shown).

Fig. (17) shows the means and SDs of forecast errors (observations-model) at the model levels for CNTR. The mean curves suggest that the model over-predicts $u$ except near the surface, but generally under-predicts v. The SD 
Table 4. Mean (M) and Standard Deviation (SD) of $u, v, T$, and $q$ Differences (CNTR - FDDA) Over the Model Domain at Every 6 Hours at (a) the Surface (b) $\sigma=$ 0.68 , and $(c) \sigma=0.32(p \approx 300 \mathrm{hPa})$

\section{(a) Surface}

\begin{tabular}{|c|c|c|c|c|c|c|c|c|}
\hline \multirow{2}{*}{$\mathbf{t}(\mathbf{h})$} & \multicolumn{2}{|c|}{$\mathbf{u}(\mathbf{m} / \mathbf{s})$} & \multicolumn{2}{|c|}{$\mathbf{v}(\mathbf{m} / \mathbf{s})$} & \multicolumn{2}{|c|}{$\left.\mathbf{T} \mathbf{(}^{\circ} \mathbf{C}\right)$} & \multicolumn{2}{|c|}{$\mathbf{q}(\mathbf{g m} / \mathbf{k g})$} \\
\cline { 2 - 9 } & $\mathbf{M}$ & $\mathbf{S D}$ & $\mathbf{M}$ & $\mathbf{S D}$ & $\mathbf{M}$ & $\mathbf{S D}$ & $\mathbf{M}$ & $\mathbf{S D}$ \\
\hline \hline 12 & -.01 & .06 & .00 & .06 & .01 & .01 & .00 & .00 \\
\hline 18 & .061 .20 & & .10 & 1.34 & .04 & .91 & .01 & .31 \\
\hline 24 & .081 .85 & & .04 & 1.86 & .01 & 1.20 & .03 & .70 \\
\hline 30 & .072 .05 & & .00 & 2.34 & .07 & .99 & .00 & 1.12 \\
\hline 36 & -.09 & 1.90 & .03 & 2.14 & .07 & .74 & -.09 & 1.28 \\
\hline
\end{tabular}

(b) $\sigma=0.68$

\begin{tabular}{|c|c|c|c|c|c|c|c|c|}
\hline \multirow{2}{*}{$\mathbf{t}(\mathbf{h})$} & \multicolumn{2}{|c|}{$\mathbf{u}(\mathbf{m} / \mathbf{s})$} & \multicolumn{2}{|c|}{$\mathbf{v}(\mathbf{m} / \mathbf{s})$} & \multicolumn{2}{|c|}{$\mathbf{T}\left({ }^{\circ} \mathbf{C}\right)$} & \multicolumn{2}{|c|}{$\mathbf{q}(\mathbf{g m} / \mathbf{k g})$} \\
\cline { 2 - 9 } & $\mathbf{M}$ & $\mathbf{S D}$ & $\mathbf{M}$ & $\mathbf{S D}$ & $\mathbf{M}$ & $\mathbf{S D}$ & $\mathbf{M}$ & $\mathbf{S D}$ \\
\hline \hline 12 & -.04 & .19 & .02 & .12 & -.01 & .05 & .00 & .00 \\
\hline 18 & .15 & 1.09 & .17 & 1.42 & .02 & .29 & .01 & .47 \\
\hline 24 & -.04 & 1.78 & .33 & 2.39 & .04 & .47 & .01 & .70 \\
\hline 30 & -.11 & 1.71 & -.24 & 1.87 & .00 & .49 & -.03 & .52 \\
\hline 36 & .09 & 1.65 & -.18 & 1.65 & .01 & .79 & .03 & .48 \\
\hline
\end{tabular}

(c) $\sigma=0.32$

\begin{tabular}{|c|c|c|c|c|c|c|c|c|}
\hline \multirow{2}{*}{$\mathbf{t}(\mathbf{h})$} & \multicolumn{2}{|c|}{$\mathbf{u}(\mathbf{m} / \mathbf{s})$} & \multicolumn{2}{|c|}{$\mathbf{v}(\mathbf{m} / \mathbf{s})$} & \multicolumn{2}{|c|}{$\mathbf{t}\left({ }^{\circ} \mathbf{C}\right)$} & \multicolumn{2}{|c|}{$\mathbf{q}(\mathbf{g m} / \mathbf{k g})$} \\
\cline { 2 - 9 } & $\mathbf{M}$ & $\mathbf{S D}$ & $\mathbf{M}$ & $\mathbf{S D}$ & $\mathbf{M}$ & $\mathbf{S D}$ & $\mathbf{M}$ & $\mathbf{S D}$ \\
\hline \hline 12 & -.00 & .03 & .00 & .03 & .00 & .00 & .00 & .00 \\
\hline 18 & .12 & 1.43 & -.02 & 1.49 & -.02 & .42 & .01 & .09 \\
\hline 24 & -.08 & 2.72 & .78 & 2.55 & .20 & .62 & .00 & .18 \\
\hline 30 & .44 & 2.76 & .18 & 2.77 & .20 & .61 & .00 & .23 \\
\hline 36 & .11 & 1.81 & -.41 & 2.55 & .13 & .53 & -.04 & .26 \\
\hline
\end{tabular}

curves suggest MM5 performs better in $\mathrm{v}$ than $\mathrm{u}$ below Level 6 (e.g; lower boundary layer and near surface). For T and q, the relatively large SDs are found near the surface (below Level 18) suggesting lower forecast skill in the model PBL. Also for this experiment, the mean values reveal that the model surface air is too warm and wet by about $1^{\circ} \mathrm{C}$ and 1 $\mathrm{gm} / \mathrm{kg}$, respectively. The $36-\mathrm{h}$ root mean square (RMS) errors of $\mathrm{u}, \mathrm{v}$, and $\mathrm{T}$ have a similar size to those of 24-h errors (for typical regional model forecasts) summarized by Anthes [16]. There are only very minor differences in the means and SDs of forecast errors between CNTR and E1. The FDDA does clearly alter the model wind, $\mathrm{T}$, and precipitation patterns, but it is difficult to determine whether such changes truly represent improvement in terms of the more conven- tional forecast error statistical measures. Nevertheless, the somewhat warmer surface $\mathrm{T}$ in the CNTR run shown in Table 4a hints that the ACARS profiles in this case tend to slightly reduce the model's warm bias.

\section{b. E2, E3, and E4}

These three experiments are designed to examine how MM5 FDDA responds to changes in the magnitude of (i) nudging parameters, (ii) radii of influence, and (iii) data density. Inter-comparison based on the means and SDs of forecast errors show minimal differences between CNTR and these three experiments. However, some interesting variations are present in the simulated $36-\mathrm{h}$ accumulated precipitation pattern as shown in Fig. (18). The basic structure and magnitudes of (CNTR-E4) and (E4-CNTR, which is not shown) strongly resemble those of (CNTR-E1) and (E1CNTR) depicted in Fig. (16). We also note that (CNTR-E2) and (E2-CNTR) shown in Fig. (18) resemble their counterparts in E3 (not shown). However, Fig. (18) does differ considerably from Fig. (16). In particular, (E2-CNTR) shows a much less organized configuration with many isolated precipitation centers. All experiments except CNTR produce an area of heavy rainfall observed on the Texas-Oklahoma border. The MM5 model appears to not be sensitive to the removal of proximate data in E4, while the model's QPF responds significantly to both the reduction of horizontal radius of influence in E2 and the change in the nudging factor in $\mathrm{E} 3$.

\section{SUMMARY}

The study is designed to test the underlying hypothesis that high frequency mesoscale FDDA using the observational nudging method can significantly improve mesoscale NWP. The work was carried out based on MM5 real-data simulation experiments in conjunction with WTM surface data and ACARS profile data. Three case studies were selected for the experiments. For each case, we conducted a control run without invoking data assimilation, several FDDA runs, and then a subsequent forecast validation.

The two WTM cases represented rather tranquil synoptic conditions over West Texas. Our findings indicated that nudging the MM5 model with surface-based data alone over such a relatively small area such as the WTM domain had limited impact on the model's performance. It is basically a three-dimensional (two horizontal dimensions plus time) assimilation. The impulses caused by the data insertion dissipated quickly within three hours after the "turning off" of nudging regardless of the length of the nudging/assimilation period. The WTM case study indicates that worthwhile mesoscale data assimilation probably requires additional vertical profile observations of the atmosphere.

The severe weather event of 8-9 May 2005 which occurred over Central Texas was selected for the ACARS experiments. Widespread precipitation was reported over Central and East Texas during the 24-h case study period. The areal means of the model's difference fields (for various meteorological parameters) between the control and individual FDDA runs showed some temporal oscillations with rela- 


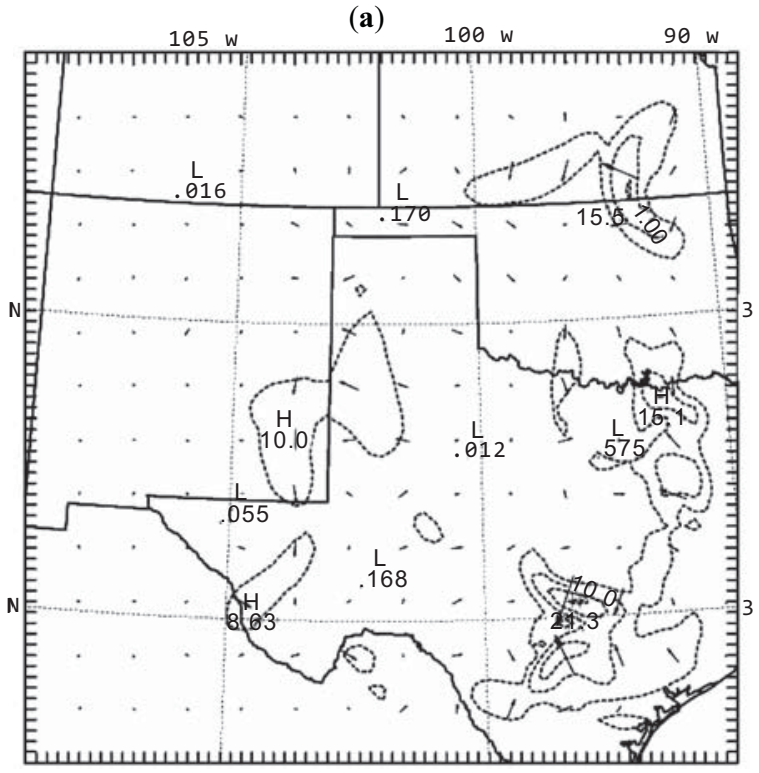

(b)

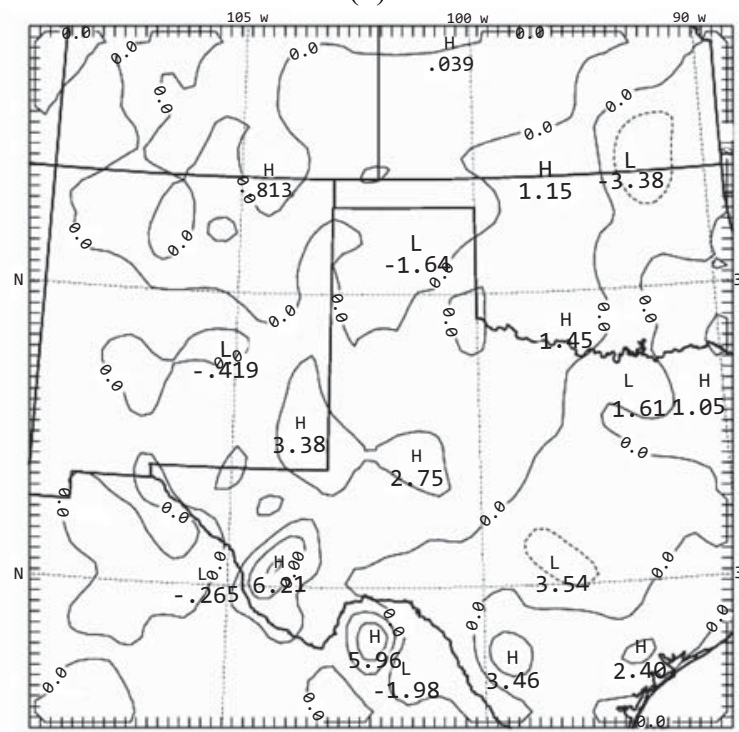

(c)

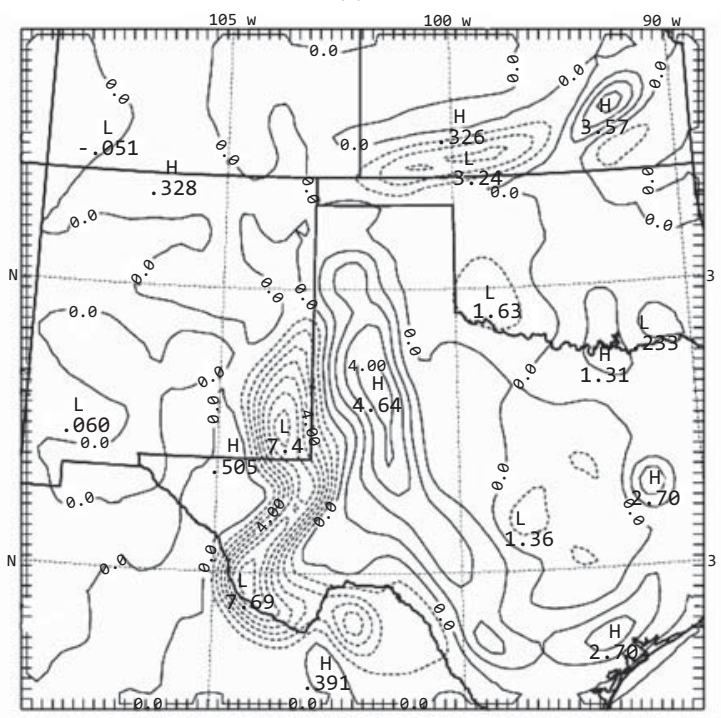

Fig. (15). 36-h differences (CNTR-E1): (a) surface winds (m/s), (b) $\mathrm{T}\left({ }^{\circ} \mathrm{C}\right)$, and $(\mathbf{c}) \mathrm{q}(\mathrm{gm} / \mathrm{kg})$. (a)

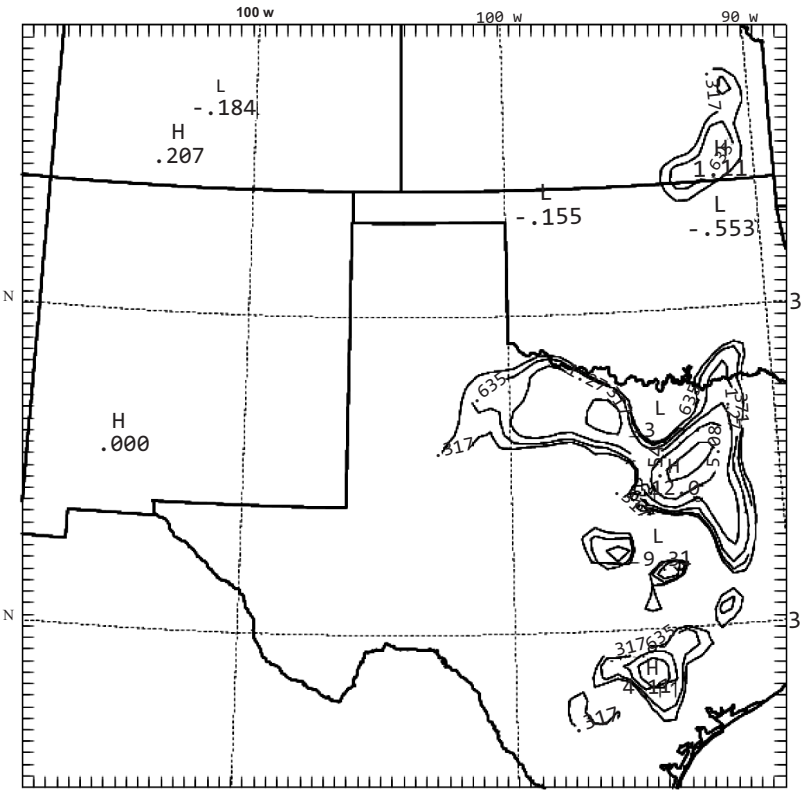

(b)

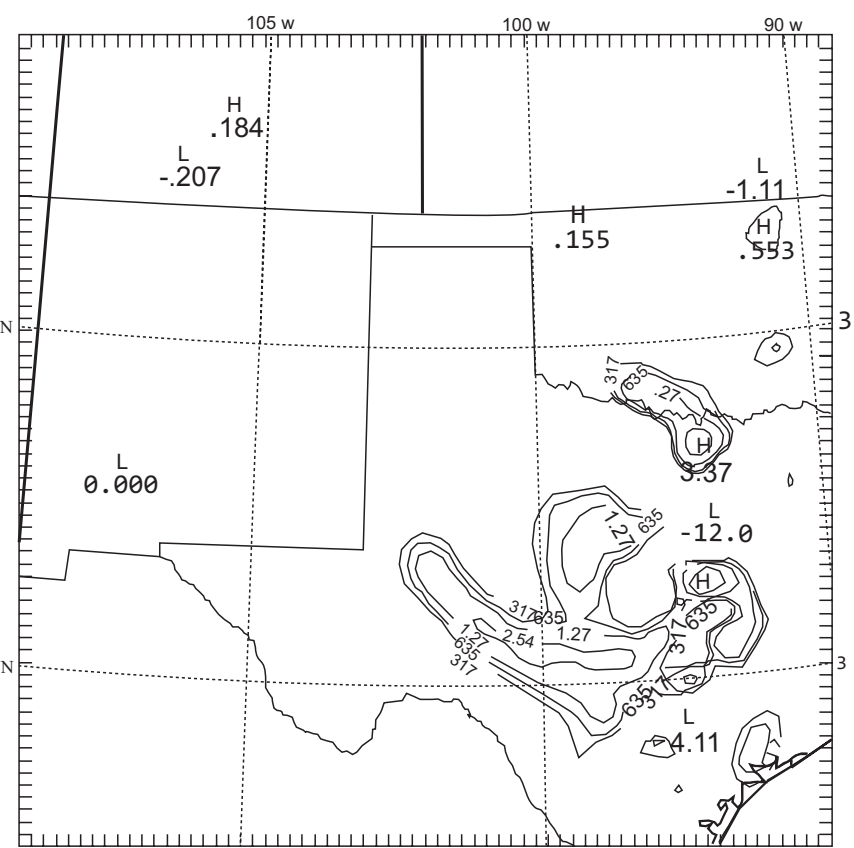

Fig. (16). $36 \mathrm{~h}$ differences in accumulated precipitation (cm): (a) CNTR-E1 and (b) E1-CNTR.

tively small amplitudes, suggesting that the model was undergoing only mild adjustments due to the insertion of the ACARS data. There was no indication of a data rejection problem. The corresponding standard deviations showed that impulses caused by insertion of the ACARS profile data had lasting impact on the MM5 forecasts throughout the entire model atmosphere, even $12 \mathrm{~h}$ after the termination of FDDA. The ACARS data distribution was not very uniform in the middle and lower layers. Nonetheless, some large changes (control minus FDDA) in the model surface flow and temperature fields were found far away from the areas where the 
(a)

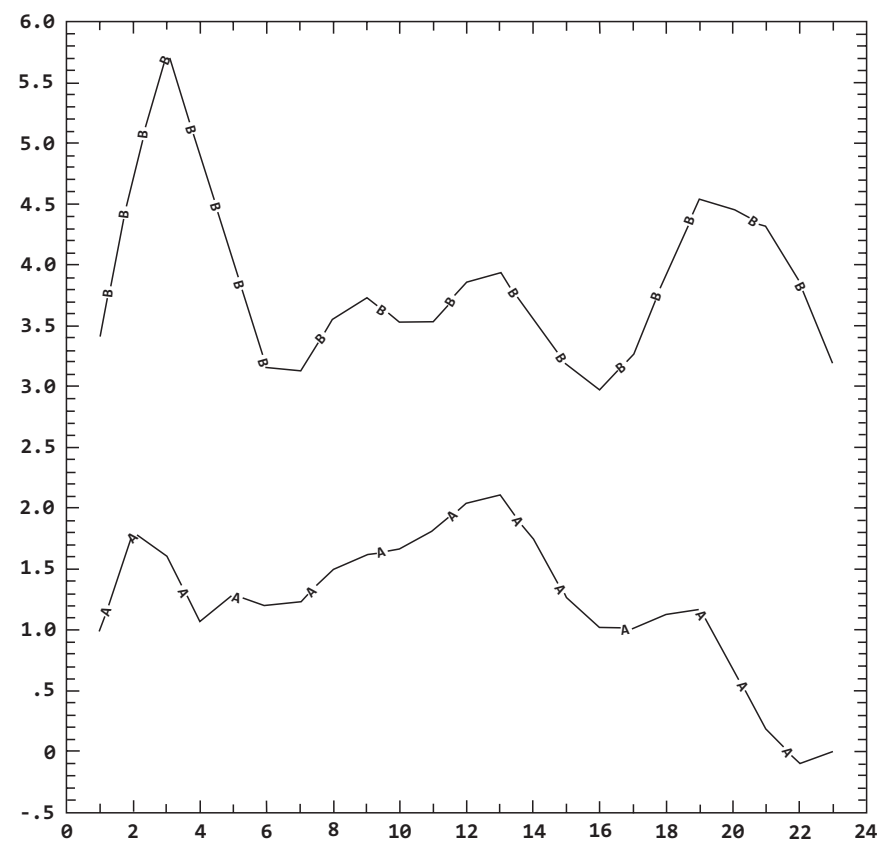

(c)

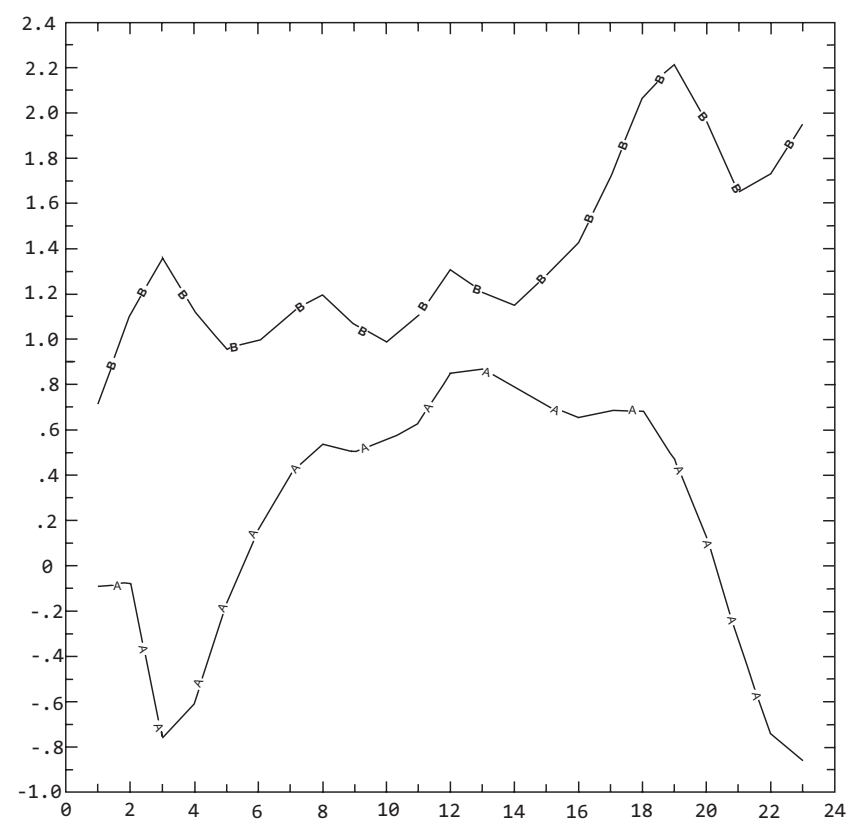

(b)

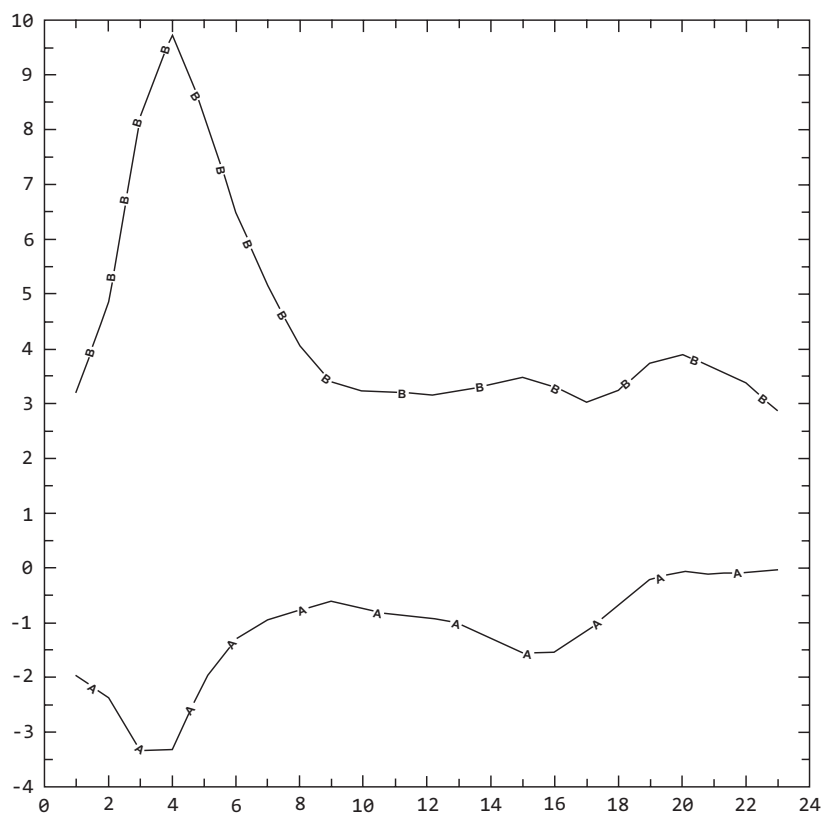

(d)

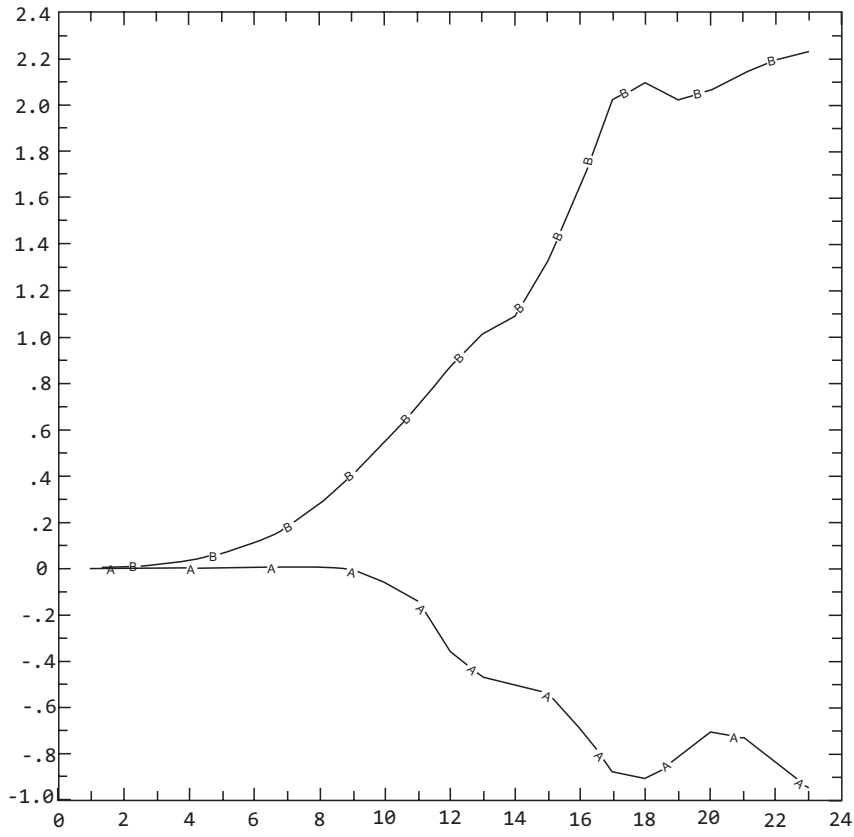

Fig. (17). Mean (Curves A, the upper ones) and standard deviation (Curves B) of differences (Observation-CNTR) at $36 \mathrm{~h}$ as a function of model levels 1 to 23 (top to bottom). (a) $\mathrm{u}$ in $\mathrm{m} / \mathrm{s}$, (b) $v$ in $\mathrm{m} / \mathrm{s}$, (c) $\mathrm{T}$ in ${ }^{\circ} \mathrm{C}$, and (d) $\mathrm{q}$ in $\mathrm{gm} / \mathrm{kg}$.

ACARS data were concentrated. While ACARS in this instance caused substantial variations in model temperature and wind forecasts, it is clearly difficult to make general statements about forecast impact (either positive or negative) and identify precisely such based on just this single case study. One positive note is that ACARS data slightly reduced the MM5's surface warm bias for this case.

FDDA appeared to improve somewhat the QPF skill of MM5. In comparison with the control run, the locations of heavy rainfall areas simulated with ACARS data in E1 verified better with the observations. The sensitivity experiments revealed a rather significant response of MM5 QPF to the changes in the nudging parameters. Some ACARS data points were located very close to each other. This could be due to multiple reports of the same data. However, averaging data within the same proximity in E1, in an attempt to avoid the possible multiple usage problems, appeared to have little effect on the model's QPF performance.

An advanced mesoscale model may perform well in some cases but not in others, and the model responses to data 
(a)

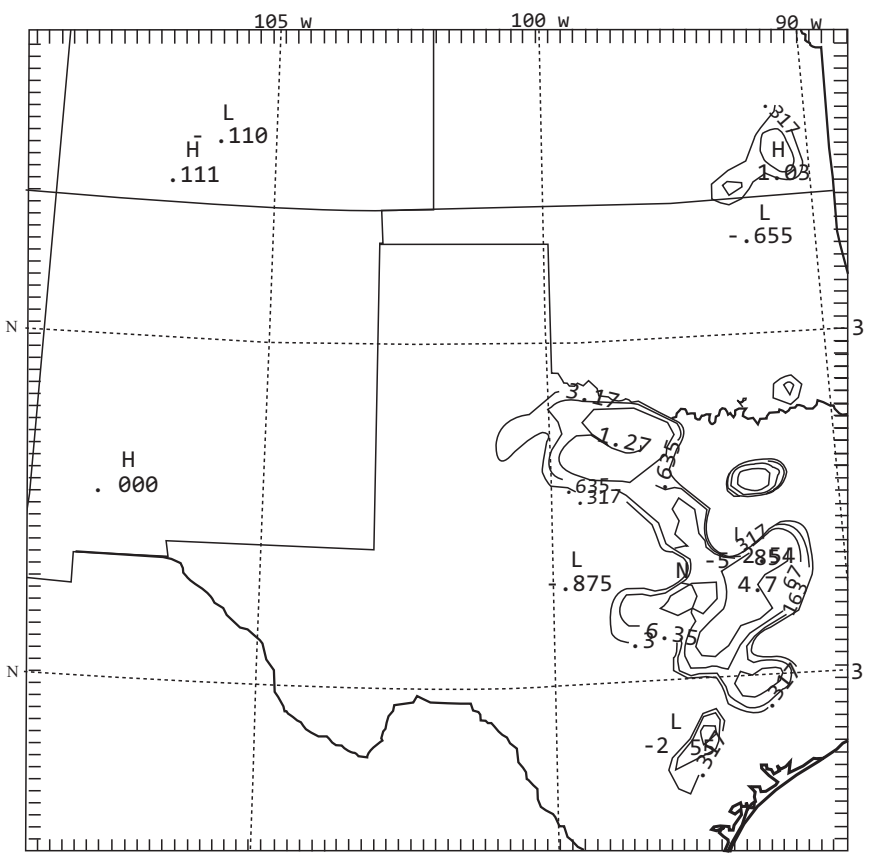

(b)

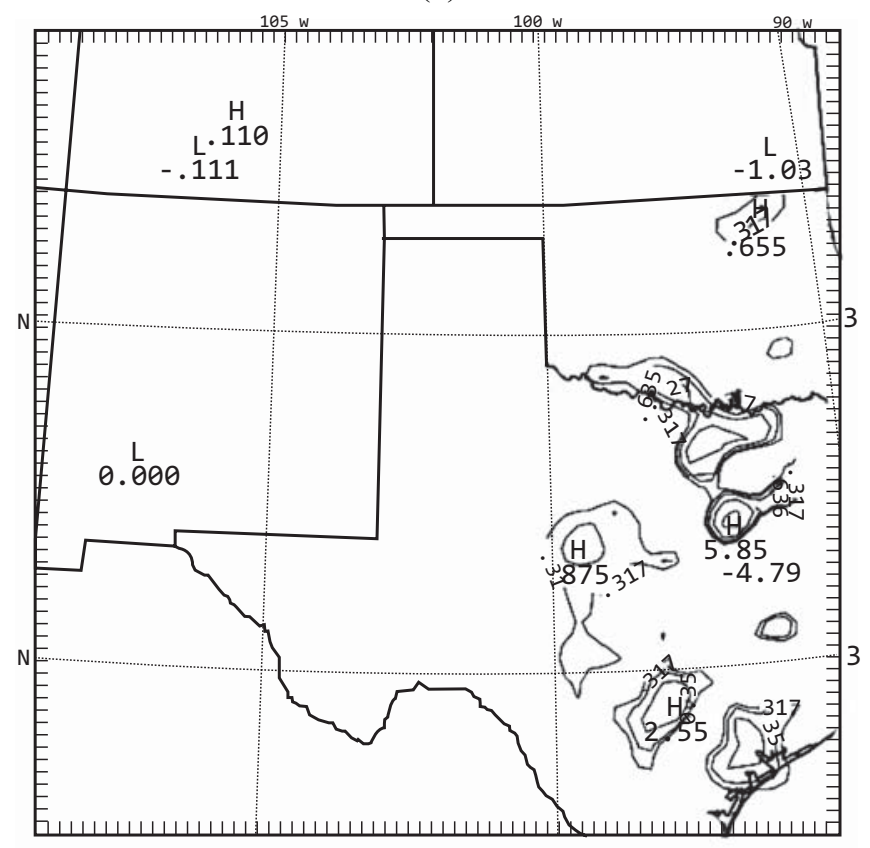

Fig. (18). As in Fig. (16), except for (a) CNTR-E2 and (b) E2CNTR.

assimilation are likely to also vary with weather scenarios and the size of data sets. Also, in modeling regions with very complex topography, it is expected that different responses and performances would be generated. The experiments still have shown that ACARS data has real potential to enhance our expertise in short-term mesoscale modeling, such as supporting the need for rapidly and accurately adjusting high-resolution meteorological model forecasts to real-time observations in an emergency response situation (as an example). More regional case studies over a wider diversity of mesoscale events (e.g., oscillating drylines, shallow arctic air incursions, flooding scenarios due to organized precipitation systems, high wind events) are desired, especially those occurring in the vicinity of the WTM domain. This will enable us to carry out a comprehensive MM5 model validation using the WTM tower T, wind, and rainfall observations. This research will hopefully allow us to reveal the most likely areas for greatest MM5 (and later, WRF) model improvement in West Texas, through the use of composite local forecast statistics derived from a large number of diverse mesoscale weather events. It may also help us to determine the optimal nudging parameters for use in our West Texas MM5 FDDA implementation in order to improve local QPF and $\mathrm{BL}$ forecasting. We would gain a physical understanding of how to capitalize upon the locally available high frequency observational data, and develop real time guidance in using these valuable data sources. Of course, running the model in other geographical regions using different sources of local observations will likely lead to different conclusions and physical/statistical relationships, so the future focus here is on model applications over our West Texas areal region.

\section{ACKNOWLEDGEMENTS}

The authors wish to acknowledge the data provided by the West Texas Mesonet team, Dr. John Schroeder and Mr. Wes Burgett at Texas Tech University, and the programmatic and management assistance of The Institute for Environmental and Human Health at Texas Tech University. Part of the study was supported by Research Development and Engineering Command (RDECOM), Department of the Army.

\section{REFERENCES}

[1] Daley R. Atmospheric data analysis, Cambridge University Press. New York: USA; 1991.

[2] Mamrosh RD. The use of high-frequency ACARS soundings in forecasting convective storms. Weather and Forecasting Conference, AMS, Phoenix, AZ, USA;1998 Jan.

[3] Sheu RS, Liu Y, Low-Nam S, Carson L. The impact of assimilating ACARS data on the performance of a real-time FDDA weather analysis and forecasting system. Symposium on Observations, Data assimilation and Probabilistic Prediction, Orlando, FL, USA; 2002 Jan.

[4] Liu Y, Vandenberghe F, Low-Nam S, Warner T, Swerdlin S. Observation-quality estimation and its application in the NCAR/ATEC real-time FDDA and forecast (RTFDDA) system. 16th Conference on Numerical Weather Prediction, Seattle, WA, USA; 2004 Jan.

[5] Grell AG, Dudhia J, Stauffer DR. A description of the fifth generation Penn State/NCAR mesoscale model (MM5). Mesoscale and Microscale Meteorology Division, NCAR, Boulder, CO, USA; 1994.

[6] Hoke JE, Anthes RA. The initialization of numerical models by a dynamic initialization technique. Mon Wea Rev 1976; 104: 1551-56.

[7] Kalnay E. Atmospheric modeling, data assimilation and predictability; Cambridge University Press: Cambridge, UK 2003.

[8] Schroeder JL, Burgett WS, Haynie KB, et al. The West Texas Mesonet: A technical overview. J Atmos Oceanic Tech 2005; 22: 211-22.

[9] Schwartz BE, Benjamin SC. A Comparison of Temperature and Wind Measurements from ACARS-Equipped Aircraft and Rawinsondes. Wea Forecast 1995; 10: 528-44.

[10] Lord RJ, Menzel WP, Pecht LE. ACARS Wind Measurements: An Intercomparison with Radiosonde, Cloud Motion, and VAS Thermally-Derived Winds. J Oceanic Atmos Tech 1984; 1: 131-37.

[11] Grell GA. Prognostic evaluation of assumption used by cumulus parameterization. Mon Wea Rev 1993; 121: 764-87.

[12] Dudhia J, Gill D, Guo YR, Hansen D, Manning K. PSU/NCAR Mesoscale Modeling System Tutorial Class Notes and User's 
Guide: MM5 Modeling System Version 2. National Center for Atmospheric Research, Boulder, CO, USA; 1998.

[13] Hong SY, Pan HL. Non-local boundary layer vertical diffusion in a medium-range forecast model. Mon Wea Rev 1996; 124: 2322-39.

[14] Black TL. The new NMC mesoscale Eta model: description and forecast examples. Wea Forecast 1994; 9(2): 265-78.
[15] Chang CB, Gill T. MM5 and HPAC experiments. Meteorol Atmos Phys 2005; 90: 127-38.

[16] Anthes RA. Regional models of the atmosphere in middle latitudes. Mon Wea Rev 1983; 111: 1306-35.

(c) Chang and Dumais; Licensee Bentham Open.

This is an open access article distributed under the terms of the Creative Commons Attribution License (http://creativecommons.org/licenses/by/2.5/), which permits unrestrictive use, distribution, and reproduction in any medium, provided the original work is properly cited. 